\title{
Life Cycle Greenhouse Gas Impacts of a Connected and Automated SUV and Van
}

\author{
By \\ Nick Kemp \\ A thesis submitted in partial \\ fulfillment of the requirements for the \\ degree of Masters of Science \\ (Environment and Sustainability) at \\ the University of Michigan
}

April 2020

Thesis Committee:

Professor Gregory A. Keoleian, Chair

Dr. Xiaoyi He, Research Fellow 



\section{Acknowledgements}

I would like to thank Dr. Gregory Keoleian for his efforts to make this thesis project possible. His wisdom, experience and support ensured the technical rigor and accuracy of the analysis. Additionally, his work ethic, selflessness, and passion for sustainability helped to drive this project to the finish line. Dr. Keoleian has been a strong advisor, mentor and coach. I would also like to express gratitude to Akshat Kasliwal and Dr. Xiaoyi He for their technical and moral support, without which this project would not have been possible. This research was supported by the following grant from Argonne National Laboratory to the Center for Sustainable Systems at the University of Michigan: ANL Grant\# 7F-30052 \& U.S. DOE Award \# DE-AC02-06CH11357. In addition, I wish to acknowledge the following for their helpful contributions: Morteza Taiebat for his insights on existing automated vehicle research, Dr. Jarod Kelly at Argonne National Laboratory for sharing his expertise with GREET and insight on automated vehicles, Dr. Hyung Chul Kim at Ford Motor Company for sharing his technical expertise, Mr. Jim Gawron at the University of Michigan for helpful discussions and foundational research on automated sedans, Greg McGuire at Mcity for sharing information on sensor technology and suppliers, and Dr. Geoff Lewis and Helaine Hunscher for their support and advice throughout my graduate school experience. 


\section{Preface}

The connected and automated vehicle (CAV) is a fundamentally disruptive technology that will change the future of mobility. Existing studies that evaluate the environmental impacts of CAV technology focus on light duty passenger cars (sedans); little is known about its impact on sport utility vehicles (SUVs) and vans. This thesis research applies life cycle modeling methodology to understand greenhouse gas emissions and primary energy use of a CAV SUV and van deployed as a ridesource fleet vehicle. Our focus on SUVs and vans as ridesourcing fleet vehicles in this study is motivated by two major market trends: 1. Increasing SUV sales and 2. An increase in usage of ridesourcing services. The results of this research show that current automated vehicle technology does not provide a direct path to reducing vehicle life cycle GHG emissions. The work presented in this thesis was submitted for publication in the journal Transportation Research Part D: Transport and the Environment. The publication decision is still pending at this time. 
Table of Contents

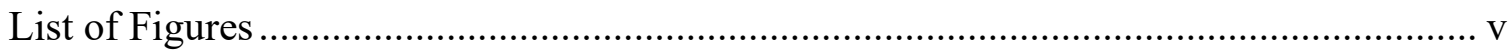

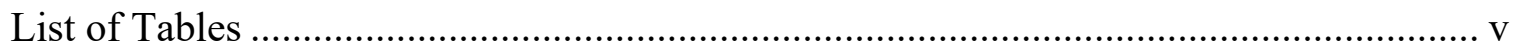

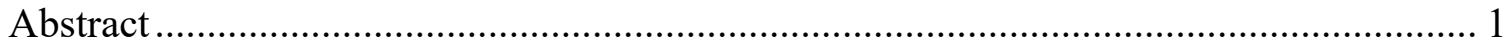

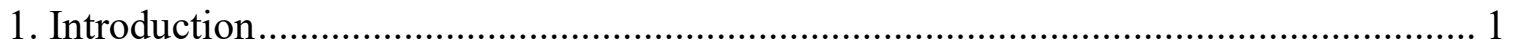

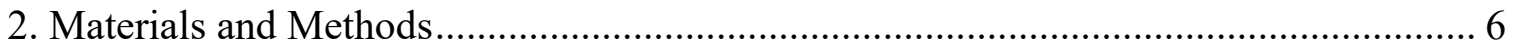

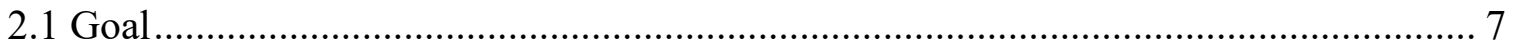

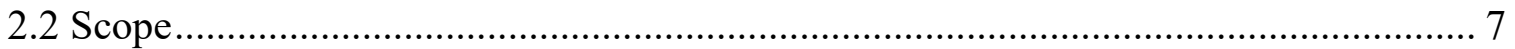

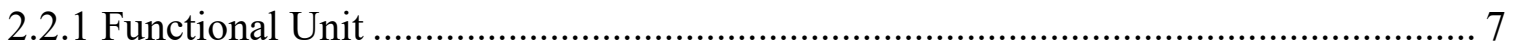

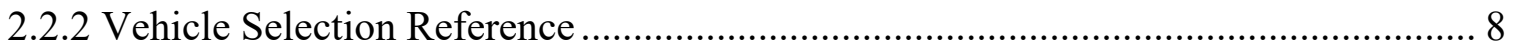

2.2.3 Subsystem Component Selection.................................................................... 9

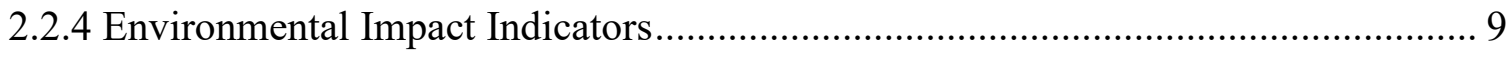

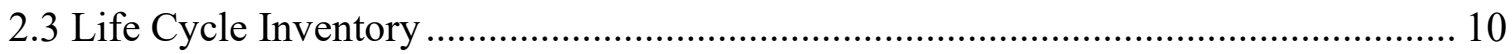

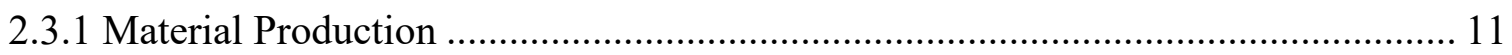

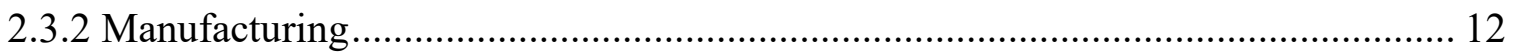

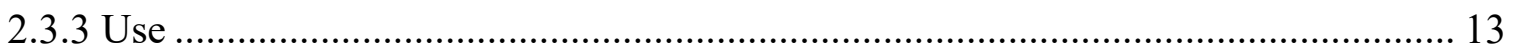

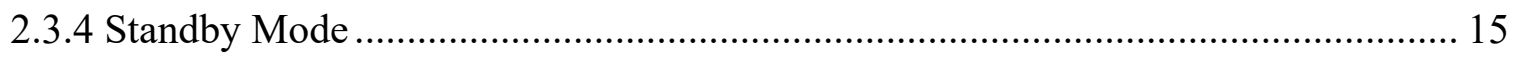

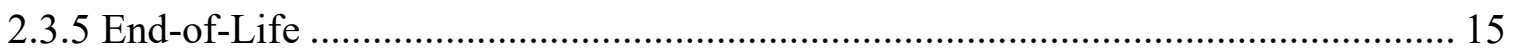

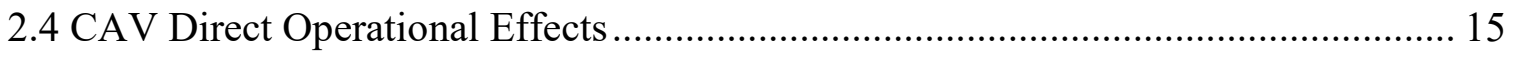

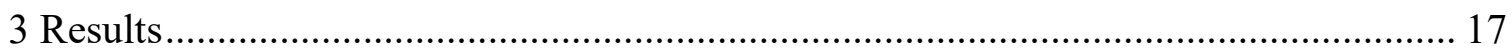

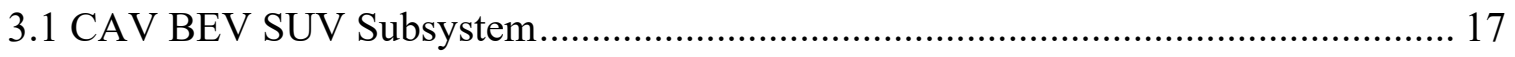

3.2 CAV BEV SUV Subsystem Life Cycle Phase Breakdown ...................................... 19

3.3 CAV BEV SUV Vehicle Level....................................................................... 20

3.4 CAV ICEV Van Vehicle Level...................................................................... 21

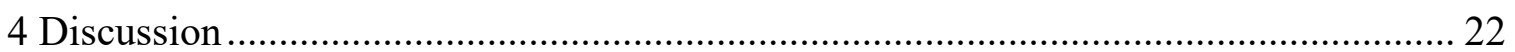

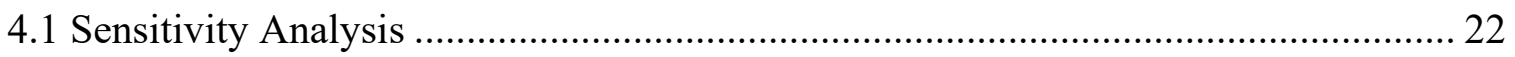

4.2 Future Research \& System Level Impacts .............................................................. 24

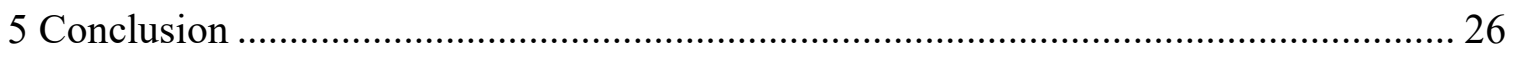

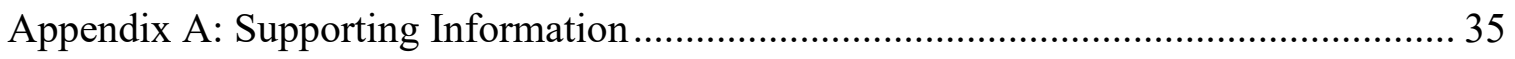

rm, CAV subsystem and the benefits of direct effects for the BEV platform .................. 36 


\section{List of Figures}

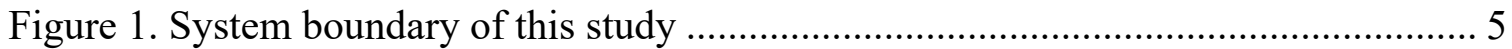

Figure 2. Percent breakdown of CAV BEV subsystem emissions ................................... 18

Figure 3. CAV BEV SUV component emissions ………........................................... 19

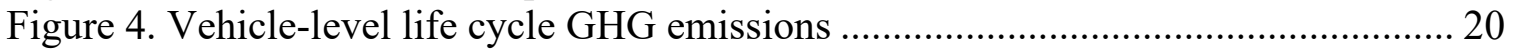

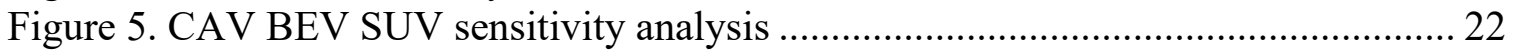

\section{List of Tables}

Table 1. Level 4 CAV sensing and computing subsystem architecture ........................... 9

Table 2. Model, weight, power demand, and GHG emissions ........................................ 11

Table 3. Changes in operational efficiencies ................................................................... 16 


\begin{abstract}
As technological advancements progress, the automotive industry is getting closer to producing Level 4 connected and automated vehicles (CAVs). Market trends show personal vehicle sales moving towards sport utility vehicles (SUVs) and increasing use of ridesourcing services. We conducted a life cycle assessment (LCA) of Level 4 CAV subsystem components integrated into battery electric vehicle (BEV SUV) and internal combustion engine vehicle (ICEV van) platforms. Vehicle lifetime was modeled based on deployment as an automated taxi, incorporating a standby mode to account for continuous connectivity. This study explores impacts of weight, drag, and subsystem electricity demand relative to benefits of eco-driving, platooning, and intersection connectivity at the vehicle system level. A CAV BEV coupled with a low carbon intensity grid $\left(0.08 \mathrm{~kg} \mathrm{CO}_{2} \mathrm{e} / \mathrm{kWh}\right)$ could see a $31 \%$ decrease in life cycle greenhouse gas (GHG) emissions while a CAV BEV with high computing power requirements $(4000 \mathrm{~W})$ could see an increase in GHG emissions of 34\% compared with the base case. The net result for the base case (500 $\mathrm{W}$ computer power, 14\% operational efficiency improvement, $45 \%$ highway driving) CAV shows an increase in primary energy use and GHG emissions $(2.7 \%, 2.7 \%$ for BEV; $1.3 \%, 1.1 \%$ for ICEV) compared with non-CAV platforms.
\end{abstract}

\title{
1. Introduction
}

The transportation sector is the largest contributor (29\%) to total U.S. greenhouse gas (GHG) emissions.(“Source of Greenhouse Gas Emissions,” 2019) It has been the leading 
sector since 2017 when it surpassed the electric power industry. ("Greenhouse Gas Inventory Data Explorer," 2018) The Connected and Automated Vehicle (CAV) is fundamentally a disruptive technology that could shape the future of mobility.(Hinkle et al., 2017) Therefore, it is imperative to understand the sustainability implications of this emergent system. CAVs could see considerable market penetration and consumer adoption in the next few decades.(Bansal and Kockelman, 2017) Many commercial vehicles already come equipped with enabling features such as lane departure warning, adaptive cruise control, blind spot monitoring, and parking assist. CAV adoption scenarios could range from personal vehicle ownership to utilization in urban automated taxi services.(Greenblatt and Shaheen, 2015) Studies indicate that initial adoption could be in the form of shared mobility services(Narayanan et al., 2020) with companies already demonstrating self-driving taxis in cities such as Austin and Las Vegas.(Bansal and Kockelman, 2017; McCall, 2019)

Existing studies that evaluate the environmental impacts of CAV technology focus on light duty passenger cars (sedans); little is known about its impact on sport utility vehicles (SUVs) and vans. SUVs and vans have greater environmental burdens in production and use phase relative to sedans.(GREET, 2016) Our focus on SUVs and vans as ridesourcing fleet vehicles in this study is motivated by two major market trends. First, the automotive market is increasingly trending towards SUVs, with countries including Russia, France, the UK, and the United States seeing 2018 growth in SUV sales exceed 10\%.(Munoz, 2019) SUVs accounted for 48\% of all new vehicle sales in 2018.("U.S. new vehicle sales saw a slight increase in 2018 as SUVs continue to see market share growth," 2019) Additionally, SUV manufacturing in the U.S. grew 7\% annually from 
2014 to 2019. (Savaskan, 2019) As such, initial CAVs are also expected to be SUVs or passenger vans. They offer passengers greater comfort and allow for higher occupancy. The second underlying market trend is the increase of ridesourcing services; from 2013 2016, Uber and Lyft realized a 150\% increase in annual vehicle miles traveled.(Hensley et al., 2017) It is predicted that automated vehicles could drastically affect how personal vehicles are used.(Fox-Penner et al., 2018) Uber has seen a 220\% increase in active users from 2016 to 2019.("Monthly number of Uber's active users worldwide from 2016 to 2019,” 2019) A study has shown a correlation between increased penetration of CAVs with increased ridesourcing.(Soteropoulos et al., 2019) While Gawron et al. (2018) conducted a life cycle assessment on the energy use and GHG impact of CAV sensing and computing subsystems for sedans, there is a gap in the literature of understanding the full life cycle implications of these subsystems on SUVs and vans.(Gawron et al., 2018) Studies show that potential benefits from the deployment of CAV vehicles will be improved when combined with shared mobility services. (Taiebat et al., 2018) With global $\mathrm{CO}_{2}$ emissions from the transportation sector expected to double by 2050 (over 2010 emissions) (Metz et al., 2014)it is important to understand the impacts of this emerging technology to better inform the development and deployment of CAV SUVs and vans.

We report the first comprehensive analysis of primary energy use and GHG emissions impacts of CAV SUVs and vans, providing a life cycle assessment (LCA) of CAV sensing and computing subsystems for both internal combustion engine vehicle (ICEV) and battery electric vehicle (BEV) platforms. The ICEV is modeled as a passenger van and the BEV is modeled as an SUV. Given trends of growing SUV sales, increasing 
utilization of ridesourcing services, and studies showing potential effects of CAV deployment as a shared transportation service we seek to understand the environmental impacts of a CAV with vehicle mileage and lifetime modeled based on service as an automated taxi.(Alonso-Mora et al., 2017) SAE International defines Level 4 CAVs as capable of automated driving under a specific set of conditions that will not require a human to ever take control.(Taxonomy and Definitions for Terms Related to Driving Automation Systems for On-Road Motor Vehicles, 2016) Predictions for when Level 4-5 vehicles are expected to achieve high penetration vary greatly, ranging from 2030 (Greenblatt and Shaheen, 2015) to 2050 (Todd Litman, 2019) to as far out as 2075 (Shladover, 2016). Our study serves to understand the production, use, and end-of-life (EOL) phase impacts of predicted Level 4 CAV subsystems on SUVs and vans.

Both direct and indirect effects determine energy use and life cycle GHG emissions outcomes which are highlighted in Error! Not a valid bookmark self-reference.. 


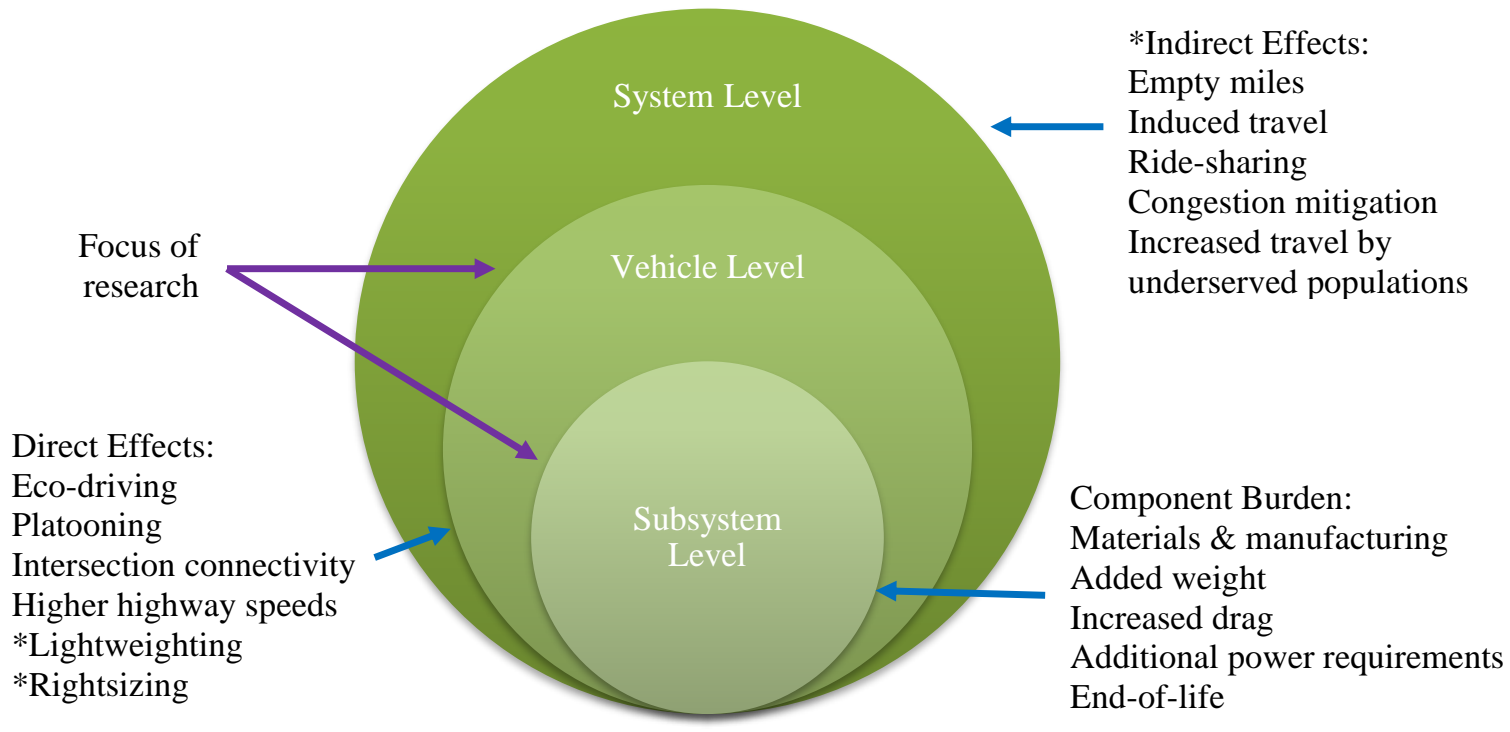

Figure 1. System boundary of this study and depiction of CAV impacts (adapted from Gawron et al. 2018). Direct effects assessed in this study are eco-driving, platooning, intersection connectivity and higher highway speeds. *Not considered for this study: lightweighting and rightsizing as well as system-level impacts (empty miles, induced travel, ridesharing, etc.) but shown for informational purposes.

Direct effects are those that can be specifically attributed to vehicle automation. They include eco-driving, platooning, higher highway speeds, lightweighting, and rightsizing.(US Energy Information Administration (EIA), 2018) A specific subset of direct effects realized from (or directly related to) CAV technology are assessed in this study; they are eco-driving, platooning, intersection connectivity, and higher highway speeds. Indirect effects such as reduced driving to locate parking, ridesharing, congestion mitigation, higher travel demand due to reduced travel cost and increased travel by underserved populations are also important.(Study of the Potential Energy Consumption Impacts of Connected and Automated Vehicles, 2017) However, we do not address 
indirect effects in this study as they are system-level effects that are outside of our research scope. The boundaries of this study are set at vehicle level impacts. Note that additional, wide-ranging mobility system impacts (empty miles, induced travel demand, etc.) could indirectly be accelerated by CAV technology. These additional impacts might also be realized through modes other than CAV deployment including congestion mitigation and ridesharing, as well as external influences such as new policies and regulations.(Henaghan, 2018)

Although progress continues in CAV technology development and deployment, previous studies show that large uncertainties exist when conducting LCA for emerging technologies.(Miller and Keoleian, 2015) These uncertainties pose particular challenges for this analysis, the precision of which is limited by available data regarding CAV subsystem composition, equipment production, CAV adoption scenarios, and real-world efficiencies realized from direct effects. Sensitivity analysis was conducted to explore uncertainties and enhance the understanding of the impact of variation based on a range of scenarios and model input parameters.

\section{Materials and Methods}

This study utilized an LCA framework applying principles from the Gawron et al. 2018 sedan model to understand cradle-to-grave primary energy use and GHG emissions. Additional life cycle impacts such as ozone depletion, acidification, and human toxicity are not presented due to lack of available subsystem component data for these impact characterizations. The results encompass the following life cycle phases: material production, manufacturing and assembly, use, and EOL. 


\subsection{Goal}

The goal of this study is to estimate the life cycle primary energy and GHG emissions at a vehicle systems level of a CAV SUV and van being used as an automated taxi fleet vehicle and understand how the impacts of CAV subsystems on an SUV or van compare to those on a sedan. The analysis includes CAV direct effects as well as energy requirements and GHG emissions associated with subsystem component production, use, and EOL management.

\subsection{Scope}

This study analyzes life cycle energy usage and GHG emissions of a CAV BEV SUV and a CAV ICEV van in use as an automated taxi fleet vehicle. It also provides a comparison of the CAV BEV SUV to a CAV BEV sedan. The results of the SUV are compared with sedan results from Gawron et al., 2018, the latter of which is updated to include more recent material production emission profiles, new CAV technologies available, and additional standby mode energy demand. The vehicle models include a subsystem necessary to achieve Level 4 automation status based on current industry understanding and technology including LiDAR, radar, and cameras as well as other sensing and computing components.

\subsubsection{Functional Unit}

The functional unit(s) for this study is a five passenger taxi fleet vehicle (SUV or van) with a service life of 200,000 miles traveled over 3 years.(Gawron, 2019) The lifetime was calculated based on a simulated ridesourcing model showing an average of 188 miles traveled per day.(Alonso-Mora et al., 2017) 


\subsubsection{Vehicle Selection Reference}

We reviewed EV SUV and ICEV van models available in 2019, which led us to conclude that there were no full-sized BEV SUVs we could model. Due to this limitation, we considered all vehicles that were marketed as SUVs. We narrowed potential candidates to those that were most similar to the GREET EV SUV and ICEV light-duty truck, in order to analyze a CAV BEV SUV and a CAV ICEV van. Ultimate vehicle selections were then made based on the similarity of shape, weight, fuel economy, passenger capacity, and likeness to the GREET 2018 SUV. As such, our modeling had to be limited to a crossover SUV.

The BEV platform is modeled as the 2019 Kia Niro Electric and the ICEV platform is modeled as the 2019 Ford Transit Connect 4-Cylinder Automatic. The 2019 Kia Niro most closely matched the GREET 2018 BEV SUV option. It weighs 3,854 pounds while the GREET 2018 BEV SUV has a simulated weight of 4,085 pounds. We also evaluated the fuel economy of the Kia Niro, listed as $112 \mathrm{MPG}_{\mathrm{e}}$ which approximates to the GREET SUV model with a fuel economy of $109 \mathrm{MPG}_{\mathrm{e}}$. The 2019 Ford Transit Connect, the ICEV van used in this study, weighs 4,025 pounds. We selected this vehicle based on a similar size, shape, weight and carrying capacity as the 2019 Kia Niro and its similarity to the GREET 2 ICEV Conventional SUV model with a weight of 3,882 pounds. Vehicle range was also considered for selection. The 2019 Kia Niro has a 64 kWh lithium-ion battery. We modeled the same battery size for the GREET BEV SUV. This provides a 239-mile range, sufficient for almost all regular daily trips.(Barry, 2019; He et al., 2019) 


\subsubsection{Subsystem Component Selection}

The CAV subsystem was determined based on a compositional analysis of subsystem architectures across varying makes and models of current automated prototypes.

Additionally, primary data for the number and type of sensors incorporated on the NAVYA driverless shuttle were provided by the University of Michigan's Mcity. The Level 4 CAV subsystem architecture is summarized in Table 1. It includes sensors, computers, wire harnesses, and supporting structures. Specific sensor models representing each sensor type are chosen from industry-leading suppliers; these do not necessarily represent hardware in use on any specific vehicle. It was assumed that no additional control hardware is needed beyond the existing drive by wire systems of the platform vehicles.

Table 1. Level 4 CAV sensing and computing subsystem architecture

\begin{tabular}{lr}
\hline Component & \# of units \\
\hline Camera & 8 \\
Radar & 5 \\
Large LiDAR & 1 \\
Small LiDAR & 4 \\
Integrated Inertial & 1 \\
Navigation System (INS) & \\
Dedicated Short Range & 1 \\
Communication (DSRC) & \\
Computer & 4 \\
\hline
\end{tabular}

\subsubsection{Environmental Impact Indicators}

This study reports results for two indicators based on available data as well as their importance in automotive sustainability assessment.(Jasiński et al., 2016) The first indicator is life cycle primary energy use reported in units of megajoules [MJ]. Life cycle 
GHG emissions is the second indicator and is reported in units of kilograms of carbon dioxide equivalent $\left[\mathrm{kg} \mathrm{CO}_{2}\right.$-e] on a 100-year Global Warming Potential (GWP) basis.

\subsection{Life Cycle Inventory}

The life cycle inventory was generated utilizing an attributional approach for the CAV. Table 2 provides subsystem component descriptions and inventories. Methods for estimating inventory flows for each of the life cycle phases are provided in Table 2. 
Table 2. Model, weight, power demand, and GHG emissions for each respective life cycle phase associated with CAV subsystem components

\begin{tabular}{|c|c|c|c|c|c|c|c|}
\hline Category & Camera & Radar & $\begin{array}{l}\text { Large } \\
\text { LiDAR }\end{array}$ & $\begin{array}{l}\text { Small } \\
\text { LiDAR }\end{array}$ & $\begin{array}{l}\text { GPS_IN } \\
\mathrm{S}\end{array}$ & DSRC & Computer \\
\hline Model & $\begin{array}{c}\text { Point } \\
\text { Grey } \\
\text { Dragonfl } \\
\text { y } \\
\text { 2(“Auton } \\
\text { omous } \\
\text { Vehicle } \\
\text { Uses } \\
\text { Dragonfl } \\
\text { y and } \\
\text { Firefly } \\
\text { MV } \\
\text { Cameras } \\
\text { for } \\
\text { Vision," } \\
\text { n.d., } \\
\text { "Dragonf } \\
\text { ly2 } \\
\text { Technica } \\
\text { 1 } \\
\text { Referenc } \\
\text { e Manual } \\
\text { Revision } \\
\text { 2.5,” } \\
\text { n.d.) }\end{array}$ & $\begin{array}{c}\text { Bosch } \\
\text { LRR3( } \\
\text { "LRR3 } \\
: \text { 3rd } \\
\text { generat } \\
\text { ion } \\
\text { Long- } \\
\text { Range } \\
\text { Radar } \\
\text { Sensor, } \\
\text { " n.d.) }\end{array}$ & $\begin{array}{c}\text { Velodyne } \\
\text { HDL- } \\
\text { 64E(“HD } \\
\text { L-64E," } \\
\text { n.d.) }\end{array}$ & $\begin{array}{l}\text { Velodyne } \\
\text { Alpha } \\
\text { Puck(“V } \\
\text { elodyne } \\
\text { Lidar } \\
\text { Alpha } \\
\text { Puck,” } \\
\text { n.d.) }\end{array}$ & $\begin{array}{c}\text { NovAtel } \\
\text { PwrPak } \\
7- \\
\text { E1(“'Enc } \\
\text { losures } \\
\text { PWRPa } \\
\text { k7-E1 } \\
\text { Version } \\
\text { 0B,” } \\
\text { n.d.) }\end{array}$ & $\begin{array}{c}\text { Savari } \\
\text { SW- } \\
1000(“ \\
\text { DSRC } \\
\text { Spring } \\
\text { Mount } \\
\text { ed } \\
\text { Mobil } \\
\text { e } \\
\text { Anten } \\
\text { nas } \\
5.9 \\
\text { GHz,” } \\
\text { n.d.) }\end{array}$ & $\begin{array}{c}\text { NVIDIA } \\
\text { Drive } \\
\text { Xavier(““ } \\
\text { NVIDIA } \\
\text { Drive } \\
\text { AGX,” } \\
\text { n.d.) }\end{array}$ \\
\hline Quantity & 8 & 5 & 1 & 4 & 1 & 1 & 4 \\
\hline Total Mass (kg) & 0.4 & 1.4 & 12.3 & 14.0 & 0.6 & 2.7 & 35.7 \\
\hline Total Power (W) & 16.8 & 20.0 & 60.0 & 120.0 & 2.0 & 6.0 & 885.0 \\
\hline $\begin{array}{l}\text { Materials/Manufacturi } \\
\text { ng Burden }\left(\mathrm{kg} \mathrm{CO}_{2} \text {-e) }\right.\end{array}$ & 24.7 & 119.35 & 132.1 & 234.8 & 23.4 & 83.4 & 432.1 \\
\hline $\begin{array}{l}\text { Use Phase Burden (kg } \\
\left.\mathrm{CO}_{2}-\mathrm{e}\right)\end{array}$ & 39.3 & 46.8 & 140.3 & 280.6 & 4.7 & 14.2 & 2728.0 \\
\hline $\begin{array}{l}\text { EOL Burden }\left(\mathrm{kg} \mathrm{CO}_{2-}-\right. \\
\text { e) }\end{array}$ & 0.03 & 0.10 & 0.90 & 1.0 & 0.05 & 0.19 & 2.6 \\
\hline $\begin{array}{l}\text { Total Burden }\left(\mathrm{kg} \mathrm{CO}_{2-}\right. \\
\text { e) }\end{array}$ & 64.0 & 166.22 & 273.3 & 516.4 & 28.2 & 97.8 & 3162.7 \\
\hline
\end{tabular}

\subsubsection{Material Production}

Material production energy use and emissions data were sourced from GREET 2018.(GREET, 2016) Individual component material inventories were sourced from primary data (to the extent available). When primary data were not available, weights 
were estimated using product geometry and material composition. Electronic material component burdens were determined utilizing LCA modeling results of desktop computers, laptops and tablets.(Teehan and Kandlikar, 2013) The burdens associated with the non-CAV platform vehicles were sourced directly from GREET 2018.(GREET, 2016)

\subsubsection{Manufacturing}

Manufacturing burden data was sourced primarily from GREET 2018.(GREET, 2016) Processes for fabrication of steel and aluminum parts include hot and cold rolling, casting, forging and stamping. Copper wiring was assumed to be drawn. Glass fabrication includes annealing, tempering, and laminating. Manufacturing of aluminum and steel parts included material efficiency factors of 1.38 and $1.34 \mathrm{~kg}$ of input material per $\mathrm{kg}$ of finished part respectively.(GREET, 2016)

An LCA of computer and electronic products was used to determine materials and manufacturing burdens for electronic components. Weight allocations of each component were applied to PWB, power supply, integrated circuit package, and integrated circuit die components based on data from Teehan and Kandlikar.(Teehan and Kandlikar, 2013) This allocation was then used to calculate burdens for the electronic components of all sensors and computers.

Requirements for packaging material, including cardboard and plywood, were estimated based on the size of components. Energy use and GHG emissions impacts for delivery were estimated based on shipment weight. The delivered distance was estimated for each sensor based on the distance from its manufacturing location to Detroit, MI. 
Delivery by diesel truck was assumed with a fuel intensity of $0.846 \mathrm{gal} / 100$ ton-mile. (Delorme et al., 2009)

\subsubsection{Use}

Use-phase burdens attributed to the CAV subsystem include increased energy consumption due to power requirements for sensing, computing, data transmission for navigation, increased fuel consumption due to added weight and increased drag due to externally mounted subsystem components. The vehicle lifetime and subsystem operating hours were calculated based on data from Alonso-Mora et al. 2017 modeling an automated taxi fleet of 3,000 vehicles in New York City. The average wait time between rides for the model was 120 seconds, resulting in 67,000 miles per vehicle per year.(Alonso-Mora et al., 2017) We then assumed a 55\%/45\% city/highway driving split based on the convention for fuel economy determination. Using these inputs, we calculated the vehicle lifetime and subsystem operating time to be 4,167 hours.

The BEV powers its components from the battery, charged with the local electricity grid for the base case. We used the U.S. average mix (30\% natural gas, $33 \%$ coal, $21 \%$ nuclear and 16\% others) from the GREET model.(GREET, 2016) An efficiency of $41 \%$ for primary energy to delivered electricity (well-to-tank) was used.(Kasliwal et al., 2019) A battery charge/discharge efficiency of $90 \%$ was assumed.(Cooney et al., 2013) Life cycle GHG emissions were calculated using a grid carbon intensity of $0.15 \mathrm{~kg} \mathrm{CO}_{2-}$ e/MJ.(GREET, 2016) The well-to-tank ratio for the ICEV platform sourced from GREET is $78 \%$.(GREET, 2016) Losses associated with the conversion of fuel energy to electricity for the ICEV vehicle result in overall conversion efficiency of 20\%.(Gawron et al., 2018) 
No additional power distribution systems or batteries were included in this study. The well-to-wheels carbon intensity is $0.091 \mathrm{~kg} \mathrm{CO}_{2}$-e/MJ. (GREET, 2016)

Increased fuel consumption due to increased weight also contributes to the subsystem burden. Fuel consumption of the CAV was calculated using the fuel reduction values (FRV) derived from a physics-based model using the EPA fuel economy test data of the non-CAV platform vehicles as inputs. (Kim and Wallington, 2016, 2013) The FRVs for the BEV and ICEV used in our model were 0.052 and $0.25 \mathrm{~L}$ equivalent per $100 \mathrm{~km}$ per $100 \mathrm{~kg}$.

Observed prototype vehicle and technology design trends indicate that the majority of sensors will be built into the vehicle itself, resulting in non-trivial increases in drag. Increased fuel consumption due to drag was modeled using data showing the effects of small roof racks mounted on light duty vehicles.(Chen and Meier, 2016) This study estimates an increase in fuel consumption due to drag of $0.5 \%$ based on a $45 \% / 55 \%$ split of city/highway driving.

This study assumes utilization of HD maps for CAVs. Maps data transfer power requirement for real-time HD maps is $1.24 \mathrm{MB}$ /mile.(Edwertz, 2017) This study assumes that no maps will be stored nor reused resulting in a total requirement of $248 \mathrm{~GB}$ over the vehicle lifetime. This study also assumes that $5 \mathrm{G}$ networks will be universally available and in use when Level 4 CAVs become commercially available given that $5 \mathrm{G}$ networks are already available in cities such as New York, Chicago, and Las Vegas.(Global Autonomous Driving Market Outlook, 2018, 2018; McGarry, 2019) Primary energy intensity for data transfer over the $5 \mathrm{G}$ network is $0.88 \mathrm{MJ} / \mathrm{GB}$.(Pihkola et al., 2018) The 
2019 U.S. average grid mix was used to compute life cycle GHG emissions attributable to map data transmission energy use.

\subsubsection{Standby Mode}

This study models both the CAV BEV SUV and CAV ICEV van as an individual vehicle that is part of an automated taxi fleet. It is necessary to consider the power requirements associated with maintaining $100 \%$ connectivity even when inactive (standby mode) in order to accept trip requests. This study assumes that the BEV will maintain connectivity while charging given that the Kia Niro Electric charges to $80 \%$ of its capacity in 54 minutes using DC fast charging.(Jones, 2018) Standby mode power requirements are estimated to be $30 \mathrm{~W}$ based on Tesla's user-reported data on battery depletion while the vehicle is not in use.(Alvarez, n.d.)

\subsubsection{End-of-Life}

We assume that the vehicle and CAV components are shredded at the end-of-life. Energy and GHG intensities of end-of-life management are $1.08 \mathrm{MJ} / \mathrm{kg}$ and $0.076 \mathrm{~kg}$ $\mathrm{CO}_{2}$-e/kg respectively.(GREET, 2016) This study does not include specific data on endlife-management of BEV batteries.

\subsection{CAV Direct Operational Effects}

We modeled operational efficiencies from direct effects based on the Monte Carlo simulation performed by Gawron et al., 2018 with data sourced from a 2016 NREL study.(Gawron et al., 2018; Stephens et al., 2016) A literature review and interviews with industry and research personnel revealed no recent updates with an appreciable difference 
in the estimation of efficiency gains and losses from eco-driving, intersection connectivity, platooning, and higher highway speeds. Consideration of the four direct effects results in a $14 \%$ reduction in fuel consumption. Each individual impact is displayed in Table 3 . The range of impacts is $4.5-22 \%$; we evaluate system-level results at both extremes of the range of direct effects in a sensitivity analysis.

Table 3. Changes in operational efficiencies for each of the four direct effects considered in this study(Gawron et al., 2018) (Dong et al., 2018) (Karbowski et al., 2019) (Iliev et al., 2019; Michel et al., 2016) (Stephens et al., 2016)

\begin{tabular}{lr}
\hline Direct Effect & Percent Impact \\
\hline Eco-Driving & -7 to $-16 \%$ \\
Intersection Connectivity (V2V/V2I) & -2 to $-4 \%$ \\
Platooning & -3 to $-5 \%$ \\
Higher Highway Speeds & +2 to $+8 \%$ \\
\hline
\end{tabular}

It is important to note that realization of impacts from direct effects depends upon factors such as level of automation, penetration of CAVs, and connectivity enabling infrastructure. Eco-driving is characterized by smooth acceleration, even driving pace, and smooth driving (minimizing sudden starting and stopping).(Barkenbus, 2010) Platooning is defined as a group of vehicles traveling together in a purposefully coordinated manner for the purposes of reducing fuel consumption.(Bergenhem et al., 2012) Intersection Connectivity refers to communications from vehicle-to-vehicle (V2V) as well as from vehicle-to-intersection (V2I).(Stephens et al., 2016) This communication can reduce or eliminate the need for vehicles to slow and stop at intersections thereby reducing high fuel consumption at idle or low speeds.(Zimmerman and Bonneson, 2004) Lastly, higher highway speeds would be possible due to increased safety of a transportation system dominated by CAVs. Higher highway speeds result in increased air resistance and therefore decreased fuel economy.(Brown et al., 2014) We do not evaluate 
mobility-level impacts such as modal shifts (such as walking to driving), increased travel, and empty miles traveled.(Stephens et al., 2016)

3 Results

Results are reported based on the BEV powertrain in terms of GHG emissions. Results and figures for the ICEV powertrain are discussed here.

\subsection{CAV BEV SUV Subsystem}

Emissions from each CAV BEV subsystem component are broken down by percent in Figure 2. Impacts from major contributors are discussed as follows. 


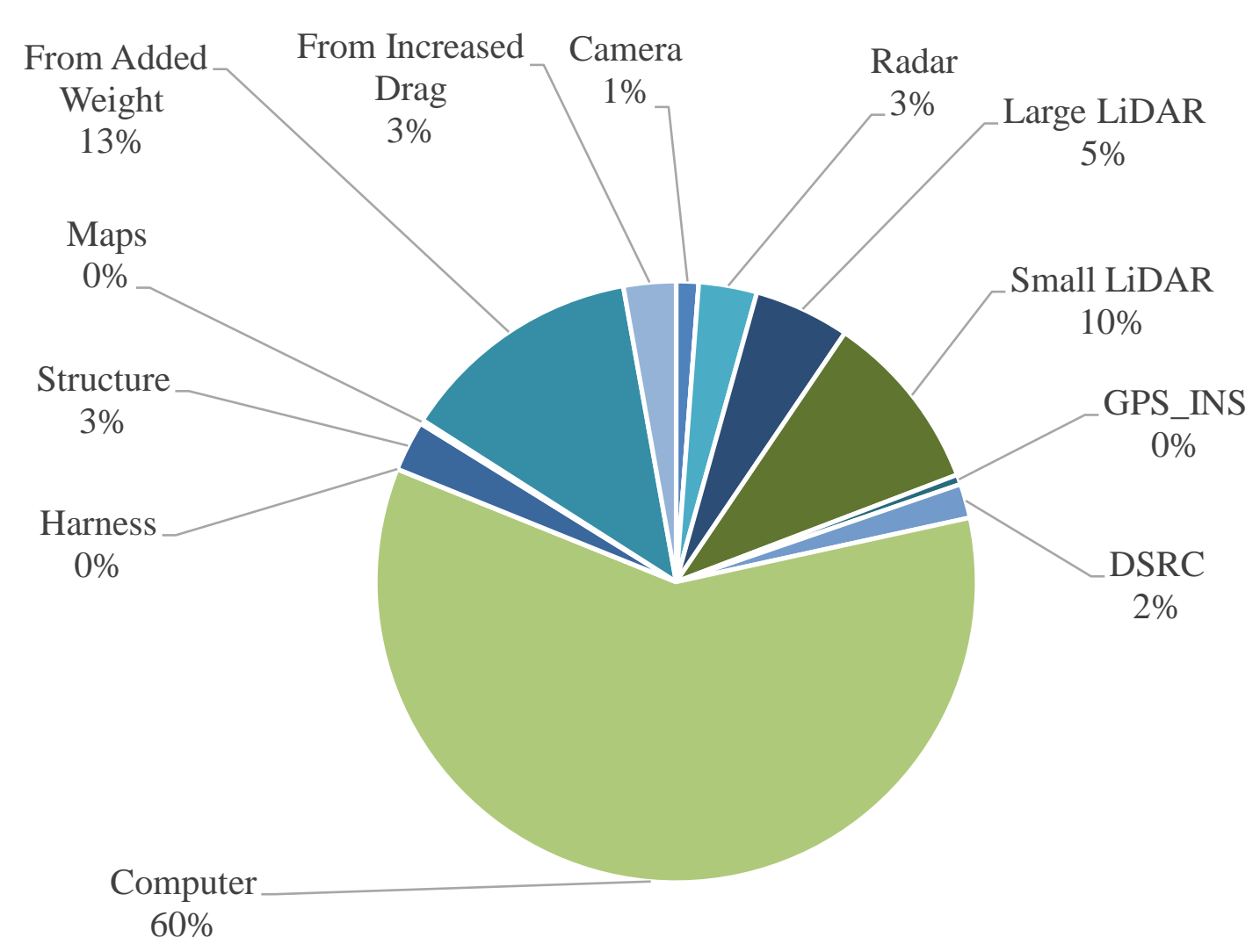

Figure 2. Percent breakdown of CAV BEV subsystem component contributions to life cycle $\mathrm{GHG}$ emissions $\left(5,300 \mathrm{~kg} \mathrm{CO}_{2}-\mathrm{e}\right)$. Values reported as $0 \%$ indicate a value $<1 \%$. Operational computing power requirements, including cooling $(0.77 \mathrm{~W}$ of cooling per watt of computing power), total $885 \mathrm{~W}$ for BEVs and ICEVs.(Lin et al., 2018) Additional computing power requirements when not in active operation (standby mode) were also accounted for. (Alvarez, n.d.) Standby mode power requirements comprise $21 \%$ of the BEV computer-related emissions and $12 \%$ of the total CAV BEV subsystem GHG emissions totaling $660 \mathrm{~kg} \mathrm{CO} 2$-e. Considering emissions from active operating, standby mode, materials and manufacturing, and end of life, the life cycle emissions of computing 
system sum up to be $3,200 \mathrm{~kg} \mathrm{CO} 2$-e, comprising $60 \%$ of the total subsystem burden $\mathrm{CO}_{2}$-e .(Alvarez, n.d.)

\subsection{CAV BEV SUV Subsystem Life Cycle Phase Breakdown}

Figure 3 depicts the component level breakdown for each phase of the BEV life cycle.

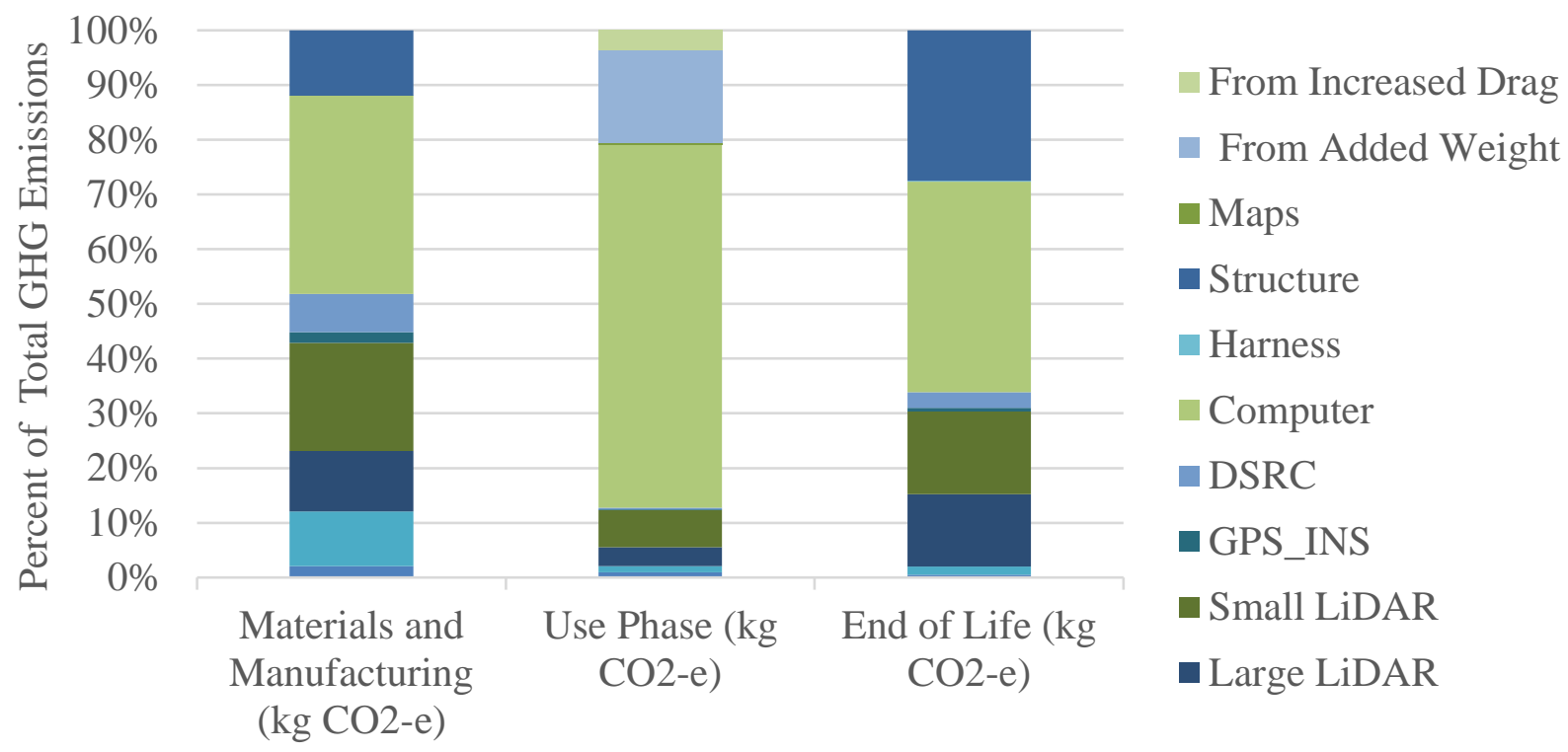

Figure 3. CAV BEV SUV platform subsystem components percent breakdown of emissions by materials and manufacturing phase, use phase, and EOL Phase $(1,200$, 4,100 , and $6.8 \mathrm{~kg} \mathrm{CO}_{2}$-e respectively)

The main contributors to emissions from the materials and manufacturing phase are the computer at $36 \%$ and the small LiDAR units at $20 \%$. The computer is the primary contributor to use phase emissions at $66 \%\left(2,700 \mathrm{~kg} \mathrm{CO}_{2}-\mathrm{e}\right)$ due to its high power requirement. The structure, due to the weight of additional materials required to mount sensors, is the main contributor to EOL emissions totaling $28 \%$. 


\subsection{CAV BEV SUV Vehicle Level}

Modeled emissions of the CAV BEV SUV subsystem are combined with the BEV SUV platform emissions to provide an understanding of the net life cycle GHG emissions as seen in Figure 4.

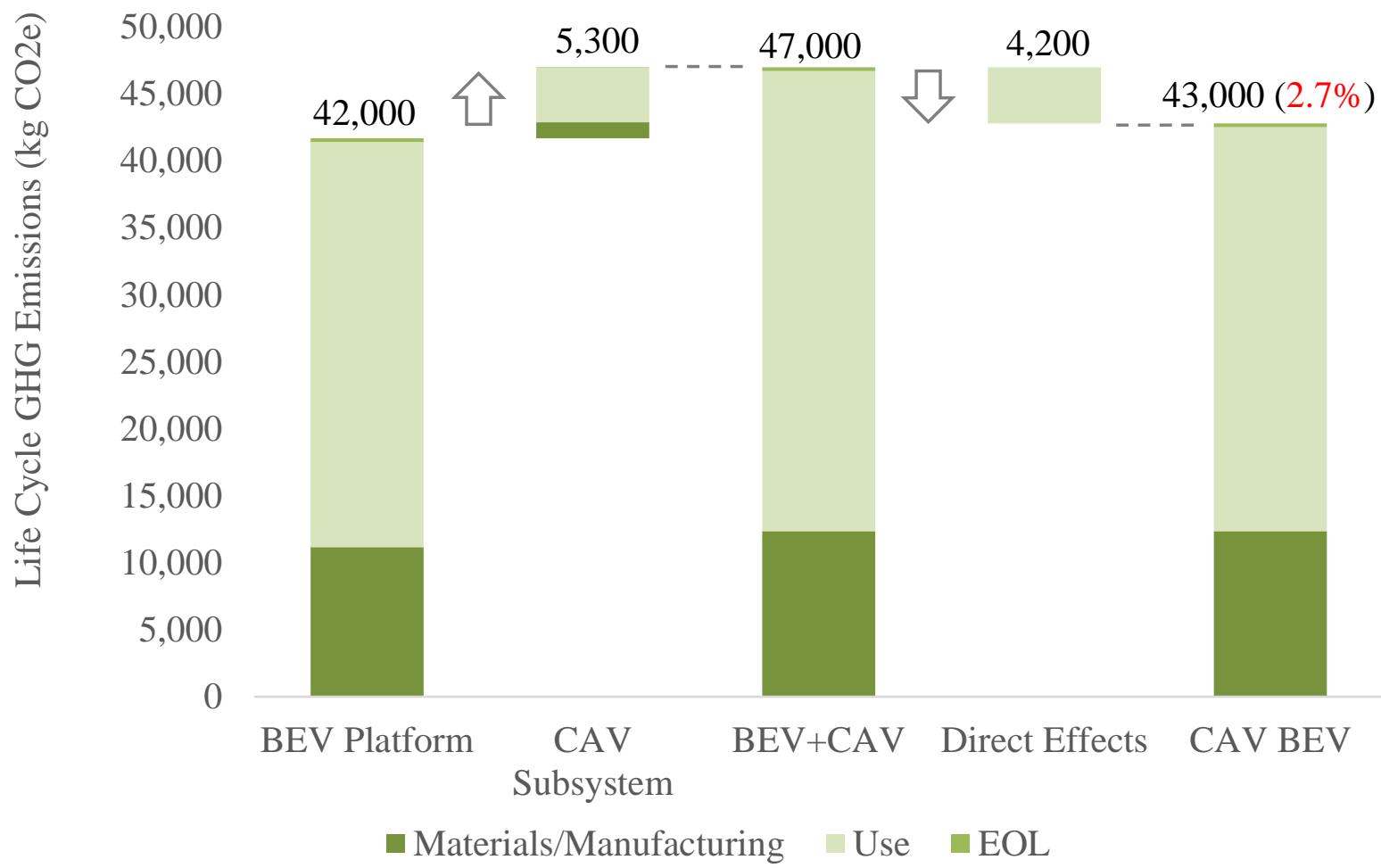

Figure 4. Vehicle-level life cycle GHG emissions depicting contributions from the vehicle platform, CAV subsystem, and the benefits from direct effects combined to show the net CAV BEV SUV GHG emissions The BEV platform emits total $42,000 \mathrm{~kg} \mathrm{CO}_{2}$-e over the 200,000-mile lifetime. The use phase is the main contributor accounting for $72 \%$ of the platform's GHG emissions given an adjusted fuel consumption rate of $30 \mathrm{kWh} / 100$ miles (112 $\mathrm{MPG}_{\mathrm{e}}$ ).("Fuel Economy," n.d.) The materials and manufacturing phase accounts for $27 \%$ of GHG emissions while the EOL phase accounts for $1 \%$. Assuming a $14 \%$ reduction in fuel consumption due to benefits from direct effects, we see a resultant decrease in emissions of 4,200 $\mathrm{kg} \mathrm{CO}_{2}$-e. 
This decrease does not fully offset the increased emissions from the subsystem itself which total 5,300 $\mathrm{kg} \mathrm{CO}_{2}$-e and result in net emissions of 43,000 $\mathrm{kg} \mathrm{CO}_{2}$-e. Vehicle level results indicate a net increase in emissions over the standard BEV platform of $2.7 \%$. These findings are consistent with the results of the CAV ICEV modeling.

\subsection{CAV ICEV Van Vehicle Level}

Modeled emissions of the CAV ICEV van subsystem are combined with the ICEV van platform emissions to provide an understanding of the net life cycle GHG emissions. The ICEV platform emits total $96,000 \mathrm{~kg} \mathrm{CO}_{2}$-e over the 200,000-mile lifetime. The use phase is the main contributor accounting for $92 \%$ of the platform's GHG emissions given an adjusted fuel consumption rate of 25 MPG.("Fuel Economy," n.d.; Kim and Wallington, 2016) The materials and manufacturing phase accounts for $7.7 \%$ of GHG emissions while the EOL phase accounts for $0.3 \%$. Assuming a $14 \%$ reduction in fuel consumption due to benefits from direct effects, we see a resultant decrease in emissions of $12,000 \mathrm{~kg} \mathrm{CO}_{2}$-e. This decrease does not fully offset the increased emissions from the subsystem itself which total $13,000 \mathrm{~kg} \mathrm{CO}_{2}$-e and result in net emissions of 97,000 kg $\mathrm{CO}_{2}$-e. This is a $1.1 \%$ net increase in life cycle GHG emissions of the CAV ICEV van over the non-CAV ICEV van. 


\section{Discussion}

\subsection{Sensitivity Analysis}

We performed sensitivity analysis on four parameters for the CAV BEV SUV and three parameters for the CAV ICEV van. Variables for analysis were selected based on uncertainty and variability. The results of the sensitivity analysis can be seen in Figure 5 .

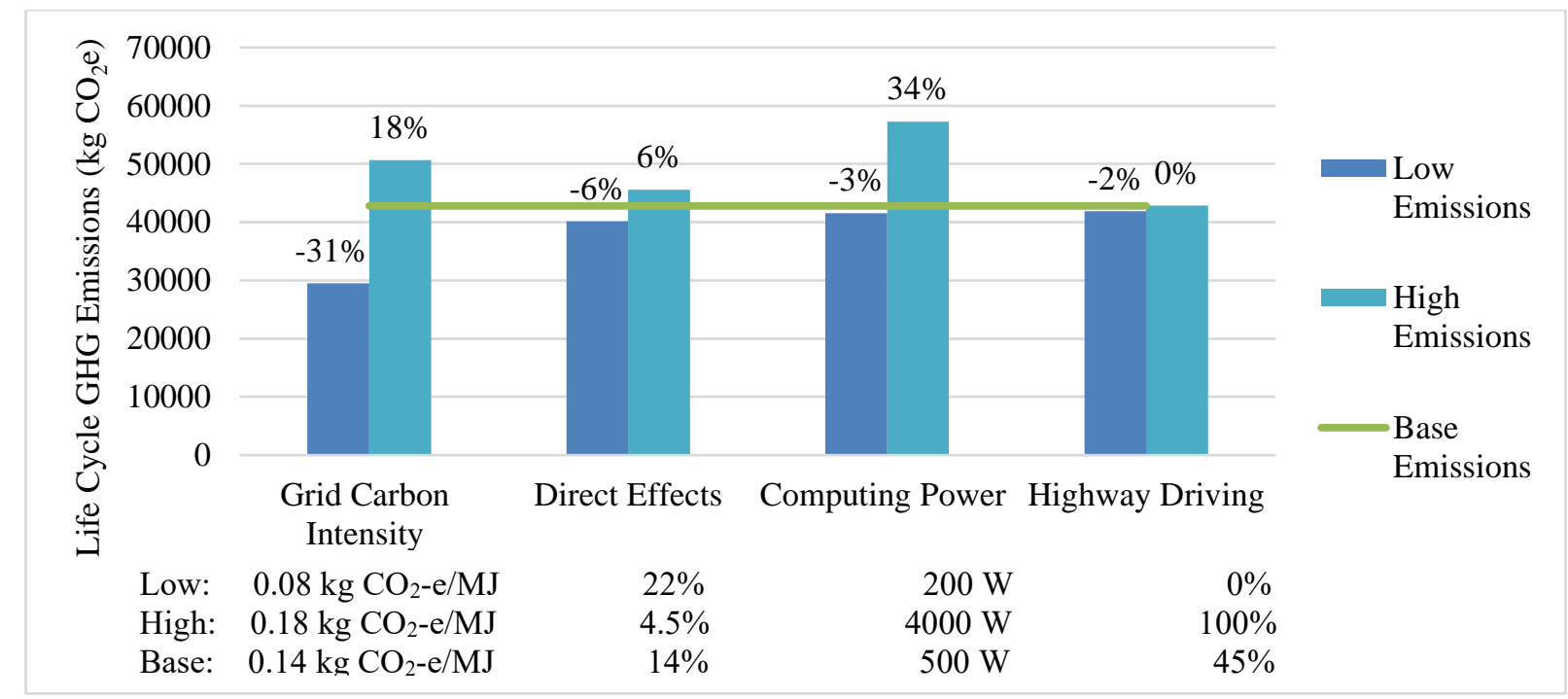

Figure 5. CAV BEV SUV sensitivity analysis results provided in terms of life cycle GHG emissions. For each variable, low and high input values were selected based on ranges found in literature or provided by industry. Percentages displayed are percent change compared to the base scenario.

The first parameter analyzed was the grid carbon intensity $\left(\mathrm{kg} \mathrm{CO}_{2}-\mathrm{e} \mathrm{MJ}^{-1}\right)$. Carbon intensity of the grid was evaluated for use-phase only. This study considered two regional U.S. grids in addition to the U.S. average grid mix. The first grid (low emissions) is the California grid with a carbon intensity of $0.08 \mathrm{~kg} \mathrm{CO}_{2}-\mathrm{e} \mathrm{MJ}^{-1}$.(GREET, 2016) This results in $31 \%$ lower life cycle GHG emissions than the base scenario. The second grid (high emissions) is the Midwest Reliability Organization (MRO) grid with a carbon intensity of 
$0.18 \mathrm{~kg} \mathrm{CO}_{2}$-e $\mathrm{MJ}^{-1}$ which results in a $18 \%$ increase in life cycle $\mathrm{GHG}$ emissions over the base scenario.(GREET, 2016) Of the four variables analyzed, grid carbon intensity has the greatest potential to reduce life cycle GHG emissions.

The second parameter examined was the direct effects. It is important to note that these operational efficiencies are highly dependent on the level of penetration of CAVs.

Research by Bansal et al., 2017 shows a wide range of predicted adoption of Level 4 CAVs extending from $25 \%$ to $87 \%$ highlighting the importance of understanding the range of impacts from direct effects.(Bansal and Kockelman, 2017) The high emissions scenario examines the lower limit of direct effects impact at $4.5 \%$. This results in a $6 \%$ increase in life cycle GHG emissions over the base scenario. Analysis of the low emissions scenario (upper limit of direct effects impact at $22 \%$ ) shows a $6 \%$ decrease in life cycle emissions. Driving penetration of CAVs is key to achieving maximum impact from direct effects and mitigation of life cycle GHG emissions.

The third parameter centered on computing power requirements. Previous work by Gawron et al., 2018 assumed a value of $200 \mathrm{~W}$. This value serves as the lower bound of this study and corresponds to 3\% lower life cycle GHG emissions for CAV SUVs than the base scenario. Interviews with industry professionals revealed an expected computing power requirement up to $4000 \mathrm{~W}$. It is important to note that in addition to the actual power requirements for the computer, power requirements for cooling are $0.77 \mathrm{~W}$ per 1 W of computing power.(Lin et al., 2018) A total power demand of $7080 \mathrm{~W}(4000+$ $4000 \times 0.77$ ) raises the life cycle GHG emissions $31 \%$ higher than the base scenario. This implies the importance of controlling computing power requirements to reduce emissions of the CAV BEV. 
The last parameter was the share of highway driving. Direct operational effects from platooning, higher highway speeds, and possible changes in computing power were assumed to have no incremental impact in this analysis. For the lower bound we analyzed the case where the vehicle is used exclusively for city driving. Direct operational effects from platooning and higher highway speeds were assumed to have an impact factor of $0 \%$ in this case. This results in a $2 \%$ decrease in life cycle GHG emissions as compared to the base scenario. The baseline BEV has a better fuel economy for city driving (123 $\mathrm{MPG}_{\mathrm{e}}$ ) than combined $45 \%$ highway, $55 \%$ city driving (112 $\mathrm{MPG}_{\mathrm{e}}$ ). The improved fuel efficiency counteracts the increased fuel consumption from increased weight which is greater in city driving than combined driving, i.e., $0.056 \mathrm{~L}_{\mathrm{e}}$ per $100 \mathrm{~kg} 100 \mathrm{~km}$ versus $0.052 \mathrm{Le}_{\mathrm{e}}$ per $100 \mathrm{~kg} 100 \mathrm{~km}$. On the other hand, a CAV BEV that travels exclusively on the highway resulted in a negligible change in life cycle GHG emissions. The latter scenario assumes that the operational effects from intersection connectivity have an impact factor of 0 , i.e. the vehicle does not realize energy saving benefits from connectivity for $100 \%$ highway driving. The highway fuel efficiency $\left(102 \mathrm{MPG}_{\mathrm{e}}\right)$ is less than the combined $45 \%$ highway, $55 \%$ city driving efficiency $\left(112 \mathrm{MPG}_{\mathrm{e}}\right)$. These increases in fuel consumption are offset by the reduced total operating hours. This analysis shows that while the impact of city driving is relatively small, increasing percent of city driving has the potential to decrease life cycle GHG emissions for the BEV.

\subsection{Future Research \& System Level Impacts}

Additional research will need to be conducted as technology and industry continue to advance CAVs. The results of this study show the importance of reducing power requirements for subsystem components as they account for $10 \%$ of the total CAV BEV 
SUV life cycle GHG emissions. Computing power requirements are the main driver at $80 \%$ of the subsystem power requirement. Subsystem Com(Meyer and Shaheen, 2017)ponent redundancy was not considered in this study due to lack of data. It is likely that commercially available Level $4 \mathrm{CAVs}$ will include redundant components for safety considerations. Future research should incorporate this data as it becomes available.

Our results show no GHG reduction benefits from CAVs at the vehicle level, because the incremental burdens from production, power consumption, and end-of-life outweigh the benefits from eco-driving, platooning, and intersection connectivity. Consequently, policies and strategies for energy saving and emission reduction should be focused at the mobility system level. Modeling of optimized fleets of automated vehicles shows that each shared automated vehicle could replace up to eleven conventional vehicles.(Meyer and Shaheen, 2017) This leads to a much faster fleet turnover with a more energyefficient fleet over time. Policies should be developed to encourage high replacement rates to reduce fleet-level energy use and emissions. Stephens et al. (2016) shows CAVs can increase vehicle miles traveled (VMT) by $20 \%$ to $160 \%$ as a result of induced travel. Policies should be implemented to limit CAV ridesourcing use to urban settings, especially for BEV CAVs which show a slight GHG emissions reduction in urban driving over the BEV base scenario in our sensitivity analysis. Additionally, policy should limit the number of ridesourcing vehicles allowed in a city. Limits could be set using modeling with real world data. For example, the work done in New York city by Alonso-Mora et al. (2017) shows that with one passenger per vehicle, an optimized ridesourcing fleet of 3,000 vehicles could replace over 13,000 taxis serving the city. Policy should also be designed to address transportation inequity issues (including improvements in public 
transportation) in an effort to increase access for underserved populations, which are prevalent in many urban areas, while minimizing induced travel for higher income populations.

Wide-scale adoption offers the opportunity to reduce congestion and traffic while also increasing transportation equity and access to underserved populations.(Henaghan, 2018) Future research should incorporate system level impacts as the mobility system level utilization of this technology will largely drive its net environmental impact.(Taiebat et al., 2018; Wadud et al., 2016) One study shows the potential of ridesourcing services (adopted by $10 \%$ of the U.S. population) to reduce local household transport-related life cycle energy use and GHG emissions by $3-5 \%$.(Chen and Kockelman, 2016)

Implementation of CAV technology should be paired with vehicle electrification and grid decarbonization, supported by the $31 \%$ net decrease in emissions over the base scenario seen in the California Grid sensitivity analysis. Our sensitivity analysis shows how the complex interaction of variables such as grid carbon intensity and computing power will drive the net impact of this technology. When the study is viewed in the larger context of the mobility system, the impact of the technology becomes even more uncertain. This further demonstrates the importance of collaboration between transportation and electric power sectors in order to strategically target opportunities to reduce overall impacts.

\section{Conclusion}

Current automated vehicle technology does not provide a direct path to reducing vehicle life cycle GHG emissions. The CAV subsystem required to reach Level 4 automation results in a net increase in life cycle GHG emissions for both the ICEV and BEV platforms. The CAV BEV SUV and CAV ICEV van are functionally equivalent 
with each vehicle capable of transporting five passengers. Comparison to the platform vehicles shows the CAV BEV has a net increase in life cycle GHG emissions of 1,000 kg $\mathrm{CO}_{2}$-e (2.7\% of total) while the CAV ICEV has a net increase of $1,100 \mathrm{~kg} \mathrm{CO}_{2}$-e $(1.1 \%$ of total). The overall life cycle GHG emissions for the CAV ICEV is 2.3 times that of the CAV BEV. Certain scenarios, such as low carbon grid intensity for CAV BEVs and $100 \%$ highway driving for CAV ICEVs show the potential to reduce vehicle level GHG emissions, $31 \%$ and $53 \%$ respectively. Nonetheless, we note that the biggest opportunity for emission reduction is dependent on vehicle electrification.

We modeled a crossover SUV because no full-sized SUV was available at the time of the study. It is expected that switching from a crossover SUV to a full-sized SUV could result in an increased materials and manufacturing burden, a decreased fuel economy, and an increased fuel reduction value (FRV). However, since these impacts expected on the CAV SUV should be roughly equivalent to the impacts on the baseline SUV, no significant changes in comparative life cycle emissions are expected.

An updated sedan model from Gawron et al. (2018) depicts a net increase in lifecycle GHG emissions of $0.32 \%$ over the platform sedan. Gawron et al. 2018 reported a net $6 \%$ decrease in emissions. One of the main reasons for this difference is the $500 \mathrm{~W}$ computing power requirement that we determined was required to achieve Level 4 automation, which is $300 \mathrm{~W}$ more than the assumption by Gawron et al., 2018. The CAV SUV shows a net $2.7 \%$ increase in life cycle GHG emissions over the platform vehicle, larger than the CAV sedan by 2.4 percentage points. While it would be preferable from an environmental standpoint to utilize sedans over SUVs, it must be recognized that sedans are not capable of performing all tasks that SUVs perform (e.g. cargo capacity, 
passenger comfort). This highlights the need to match vehicle capabilities with demand requirements.

We modeled the CAV BEV SUV as part of an automated taxi fleet. As such, we incorporated a standby mode in order to understand the impact of a continuously available vehicle. This results in an additional $660 \mathrm{~kg} \mathrm{CO}_{2}$-e $(12 \%$ of the CAV subsystem life cycle GHG emissions) over the lifetime of the vehicle. There are currently 80,000 ridesourcing and taxi vehicles in New York City. (DeBord, n.d.) With 100\% CAV penetration at current ridesourcing and taxi levels, the standby mode of these vehicles would result in annual GHG emissions totaling 53,000 metric tons of $\mathrm{CO}_{2}$-e.

The research presented in this paper reflects net life cycle GHG emissions and energy usage of a CAV BEV SUV and CAV ICEV van given current technologies and available data. While the results will change as CAV technology advances, they provide clear areas of focus for reducing environmental impacts. CAV subsystem power requirements, especially for the computer and LIDAR, must be reduced. Reducing the weight of the subsystem components will also contribute substantially to reduced life cycle GHG emissions. These vehicle level technological improvements must be made in order to realize benefits from direct effects. At a system level, vehicle electrification combined with grid decarbonization will deliver maximum benefits of CAV technologies. 


\section{REFERENCES}

Alonso-Mora, J., Samaranayake, S., Wallar, A., Frazzoli, E., Rus, D., 2017. On-demand high-capacity ride-sharing via dynamic trip-vehicle assignment. Proc. Natl. Acad. Sci. 114, 462-467. https://doi.org/10.1073/pnas.1611675114

Alvarez, S., n.d. Tesla Model 3 "Phantom Drain" Compared to Model S and Model X [WWW Document].

Argonne National Laboratory, 2016, GREET Model, https://greet.es.anl.gov/index.php

Autonomous Vehicle Uses Dragonfly and Firefly MV Cameras for Vision [WWW Document], n.d. URL https://www.ptgrey.com/case-study/id/10393?countryid=238 (accessed 8.8.19).

Bansal, P., Kockelman, K.M., 2017. Forecasting Americans' long-term adoption of connected and autonomous vehicle technologies. Transp. Res. Part A Policy Pract. 95, 49-63. https://doi.org/10.1016/j.tra.2016.10.013

Barkenbus, J.N., 2010. Eco-driving: An overlooked climate change initiative. Energy Policy 38, 762-769. https://doi.org/10.1016/j.enpol.2009.10.021

Barry, K., 2019. 2019 Kia Niro EV is Practical and Roomy [WWW Document]. Consum. Rep.

Bergenhem, C., Pettersson, H., Coelingh, E., Englund, C., Shladover, S., Tsugawa, S., 2012. Overview of platooning systems. 19th Intell. Transp. Syst. World Congr. ITS 2012.

Brown, A., Gonder, J., Repac, B., 2014. An analysis of possible energy impacts of automated vehicle, in: Road Vehicle Automation. Springer International Publishing, pp. $137-153$.

Chen, T.D., Kockelman, K.M., 2016. Carsharing's life-cycle impacts on energy use and greenhouse gas emissions. Transp. Res. Part D Transp. Environ. 47, 276-284. https://doi.org/10.1016/j.trd.2016.05.012

Chen, Y., Meier, A., 2016. Fuel consumption impacts of auto roof racks. Energy Policy 92, 325-333. https://doi.org/10.1016/j.enpol.2016.02.031

Cooney, G., Hawkins, T.R., Marriott, J., 2013. Life cycle assessment of diesel and electric public transportation buses. J. Ind. Ecol. 17, 689-699. https://doi.org/10.1111/jiec.12024

DeBord, M., n.d. Congestion pricing could mark the beginning of the end of New York's famous yellow taxis [WWW Document].

Delorme, A., Karbowski, D., Vijayagopal, R., Sharer, P., 2009. Evaluation of Fuel 
Consumption Potential of Medium and Heavy Duty Vehicles through Modeling and Simulation, Report to NAS - Contract DEPS-BEES-001.

Dong, J., Lu, C., Hu, L., 2018. Estimating Energy Efficiency of Connected and Autonomous Vehicles in a Mixed Fleet Final Report, Institute for Transportation Iowa State University.

Dragonfly2 Technical Reference Manual Revision 2.5 [WWW Document], n.d. URL www.\%0Aptgrey.com (accessed 8.8.19).

DSRC Spring Mounted Mobile Antennas 5.9 GHz [WWW Document], n.d. URL www.mobilemark.com (accessed 8.8.19).

Edwertz, O., 2017. Performance Evaluation of 5G Vehicle-to-Network Use Cases A study of site configuration and network impact. Chalmers University of Technology.

Enclosures PWRPak7-E1 Version 0B [WWW Document], n.d. URL novatel.com (accessed 8.8.19).

Fox-Penner, P., Gorman, W., Hatch, J., 2018. Long-term U.S transportation electricity use considering the effect of autonomous-vehicles: Estimates and policy observations. Energy Policy 122, 203-213. https://doi.org/10.1016/j.enpol.2018.07.033

Fuel Economy [WWW Document], n.d. . Environ. Prot. Agency. URL https://www.fueleconomy.gov/feg/PowerSearch.do?action=noform\&path=1\&year 1 $=2019 \&$ year $2=2019 \&$ make $=$ Kia\&baseModel $=$ Niro\&srchtyp $=$ ymm $($ accessed 8.8.19a).

Fuel Economy [WWW Document], n.d. . Environ. Prot. Agency. URL https://www.epa.gov/fueleconomy/text-version-gasoline-label (accessed 8.8.19b).

Gawron, J., 2019. Evaluating the Potential Environmental Impacts of Connected and Automated Vehicles. University of Michigan.

Gawron, J.H., Keoleian, G.A., De Kleine, R.D., Wallington, T.J., Kim, H.C., 2018. Life Cycle Assessment of Connected and Automated Vehicles: Sensing and Computing Subsystem and Vehicle Level Effects. Environ. Sci. Technol. 52, 3249-3256. https://doi.org/10.1021/acs.est.7b04576

Global Autonomous Driving Market Outlook, 2018, 2018.

Greenblatt, J.B., Shaheen, S., 2015. Automated Vehicles, On-Demand Mobility, and Environmental Impacts. Curr. Sustain. Energy Reports 2, 74-81.

Greenhouse Gas Inventory Data Explorer [WWW Document], 2018. URL https:/cfpub.epa.gov/ghgdata/inventoryexplorer/ (accessed 8.8.19). 
HDL-64E [WWW Document], n.d. URL www.velodynelidar.com (accessed 8.8.19).

He, X., Zhang, S., Wu, Y., Wallington, T.J., Lu, X., Tamor, M.A., McElroy, M.B., Zhang, K.M., Nielsen, C.P., Hao, J., 2019. Economic and Climate Benefits of Electric Vehicles in China, the United States, and Germany. Environ. Sci. Technol. 53, 11013-11022. https://doi.org/10.1021/acs.est.9b00531

Henaghan, J., 2018. Preparing Communities for Autonomous Vehicles.

Hensley, R., Padhi, A., Salazar, J., 2017. Cracks in the ridesharing market - and how to fill them.

Hinkle, C., Cabaniss, J., Ward, J., Gohlke, D., Nealer, R., 2017. The Transforming Mobility Ecosystem: Enabling an Energy-Efficient Future.

Iliev, S., Rask, E., Stutenberg, K., Duoba, M., 2019. Eco-Driving Strategies for Different Powertrain Types and Scenarios. SAE Tech. Pap. 1-10. https://doi.org/10.4271/2019-01-2608

Jasiński, D., Meredith, J., Kirwan, K., 2016. A comprehensive framework for automotive sustainability assessment. J. Clean. Prod. 135, 1034-1044. https://doi.org/10.1016/j.jclepro.2016.07.027

Jones, M., 2018. Everything you need to know about charging the Kia Nior EV and PHEV [WWW Document]. EV Life.

Karbowski, D., Jeong, J., Elands, K., Dobrovolschi, I., 2019. Model-Predictive EcoDriving for Electrified Connected and Automated Vehicles. EVS32 Symp. 1-11.

Kasliwal, A., Furbush, N.J., Gawron, J.H., McBride, J.R., Wallington, T.J., De Kleine, R.D., Kim, H.C., Keoleian, G.A., 2019. Role of flying cars in sustainable mobility. Nat. Commun. 10. https://doi.org/10.1038/s41467-019-09426-0

Kim, H.C., Wallington, T.J., 2016. Life Cycle Assessment of Vehicle Lightweighting: A Physics-Based Model to Estimate Use-Phase Fuel Consumption of Electrified Vehicles. Environ. Sci. Technol. 50, 11226-11233. https://doi.org/10.1021/acs.est.6b02059

Kim, H.C., Wallington, T.J., 2013. Life cycle assessment of vehicle lightweighting: A physics-based model of mass-induced fuel consumption. Environ. Sci. Technol. 47, 14358-14366. https://doi.org/10.1021/es402954w

Lin, S.C., Zhang, Y., Hsu, C.H., Skach, M., Haque, M.E., Tang, L., Mars, J., 2018. The architectural implications of autonomous driving: Constraints and acceleration. ACM SIGPLAN Not. 53, 751-766. https://doi.org/10.1145/3173162.3173191

LRR3: 3rd generation Long-Range Radar Sensor [WWW Document], n.d. URL https://www.bosch-mobility-solutions.com/en/products-and-services/passenger-cars- 
and-light-commercial-vehicles/driver-assistance-systems/left-turn-assist/long-rangeradar-sensor/ (accessed 8.8.19).

McCall, M., 2019. Why Autonomous Vehicles are Such a Game-Changer for Uber and Lyft [WWW Document]. Invest. Place. URL https:/investorplace.com/2019/03/autonomous-vehicles-game-changer-uber-lyft/ (accessed 8.2.19).

McGarry, C., 2019. What is 5G? The Definitive Guide to the 5G Network Rollout [WWW Document]. Tom's Guid.

Metz, B., Meyer, L., Bosch, P., 2014. Climate change 2014 mitigation of climate change, Climate Change 2014 Mitigation of Climate Change. https://doi.org/10.1017/CBO9780511546013

Meyer, G., Shaheen, S., 2017. Disrupting Mobility: Impacts of Sharing Economy and Innovative Transportation on Cities, Lecture Notes in Mobility. Springer International Publishing, Cham. https://doi.org/10.1007/978-3-319-51602-8

Michel, P., Karbowski, D., Rousseau, A., 2016. Impact of Connectivity and Automation on Vehicle Energy Use. SAE Tech. Pap. https://doi.org/10.4271/2016-01-0152

Miller, S.A., Keoleian, G.A., 2015. Framework for Analyzing Transformative Technologies in Life Cycle Assessment. Environ. Sci. Technol. 49, 3067-3075. https://doi.org/10.1021/es505217a

Monthly number of Uber's active users worldwide from 2016 to 2019 [WWW Document], 2019.

Munoz, F., 2019. Global SUV boom continues in 2018 but growth moderates [WWW Document].

Narayanan, S., Chaniotakis, E., Antoniou, C., 2020. Shared autonomous vehicle services: A comprehensive review. Transp. Res. Part C Emerg. Technol. 111, 255-293. https://doi.org/10.1016/j.trc.2019.12.008

NVIDIA Drive AGX [WWW Document], n.d. URL https://www.nvidia.com/en-us/selfdriving-cars/drive-platform/hardware/ (accessed 8.8.19).

Pihkola, H., Hongisto, M., Apilo, O., Lasanen, M., 2018. Evaluating the energy consumption of mobile data transfer-from technology development to consumer behaviour and life cycle thinking. Sustain. 10. https://doi.org/10.3390/su10072494

Savaskan, D., 2019. SUV \& Light Truck Manufacturing in the US. IBIS World.

Shladover, S.E., 2016. THE TRUTH “ SELF- DRIVING " CARS. Nat. Publ. Gr. 25, 7883. https://doi.org/10.1038/scientificamericansciencestories $1216-78$ 
Soteropoulos, A., Berger, M., Ciari, F., 2019. Impacts of automated vehicles on travel behaviour and land use: an international review of modelling studies. Transp. Rev. 39, 29-49. https://doi.org/10.1080/01441647.2018.1523253

Source of Greenhouse Gas Emissions [WWW Document], 2019. URL https://www.epa.gov/ghgemissions/sources-greenhouse-gas-emissions (accessed 8.8.19).

Stephens, T.S., Gonder, J., Chen, Y., Lin, Z., Liu, C., Gohlke, D., 2016. Estimated Bounds and Important Factors for Fuel Use and Consumer Costs of Connected and Automated Vehicles. Golden, CO (United States). https://doi.org/10.2172/1334242

Study of the Potential Energy Consumption Impacts of Connected and Automated Vehicles, 2017.

Taiebat, M., Brown, A.L., Safford, H.R., Qu, S., Xu, M., 2018. A Review on Energy, Environmental, and Sustainability Implications of Connected and Automated Vehicles. Environ. Sci. Technol. acs.est.8b00127. https://doi.org/10.1021/acs.est.8b00127

Taxonomy and Definitions for Terms Related to Driving Automation Systems for OnRoad Motor Vehicles, 2016. . Troy, Michigan.

Teehan, P., Kandlikar, M., 2013. Comparing embodied greenhouse gas emissions of modern computing and electronics products. Environ. Sci. Technol. 47, 3997-4003. https://doi.org/10.1021/es303012r

Todd Litman, 2019. Autonomous Vehicle Implementation Predictions: Implications for Transport Planning. Transp. Res. Board Annu. Meet. 42, 36-42. https://doi.org/10.1613/jair.301

U.S. new vehicle sales saw a slight increase in 2018 as SUVs continue to see market share growth [WWW Document], 2019. . JATO. URL https://www.jato.com/usa/us-new-vehicle-sales-saw-a-slight-increase-in-2018-as-suvs-continue-to-see-marketshare-growth/ (accessed 7.4.19).

US Energy Information Administration (EIA), 2018. Autonomous Vehicles: Uncertainties and Energy Implications: Issue in Focus from the Annual Energy Outlook 2018. Available at: https://www.eia.gov/outlooks/aeo/pdf/AV.pdf.

Velodyne Lidar Alpha Puck [WWW Document], n.d. URL https://velodynelidar.com/vls128.html (accessed 8.8.19).

Wadud, Z., MacKenzie, D., Leiby, P., 2016. Help or hindrance? The travel, energy and carbon impacts of highly automated vehicles. Transp. Res. Part A Policy Pract. 86, 1-18. https://doi.org/10.1016/j.tra.2015.12.001

Zimmerman, K., Bonneson, J.A., 2004. Intersection safety at high-speed signalized 
intersections: Number of vehicles in dilemma zone as potential measure. Transp. Res. Rec. 126-133. https://doi.org/10.3141/1897-16 
Appendix A: Supporting Information

\section{Supporting Information Includes}

Figure S1. BEV SUV vehicle level life cycle energy burden depicting contributions from the vehicle platform, CAV subsystem and the benefits of direct effects for the BEV platform.

Figure S2. ICEV van Vehicle Level life cycle energy burden depicting contributions from the vehicle platform, CAV subsystem and the benefits from direct effects for the ICEV platform....

Figure S3. ICEV van Vehicle Level GHG emissions depicting contributions from the vehicle platform, CAV subsystem and the benefits from direct effects for the ICEV platform....

Figure S4. ICEV van Subsystem contribution breakdown by percent for energy use, mass and power...

Figure S5. BEV SUV Subsystem contribution breakdown by percent for energy use, mass and power ......................................... 40

Figure S7. Comparitive subsystem component percent breakdown of emissions ( ICEV 13,000 kg CO $\mathrm{CO}_{2} \mathrm{e}, \mathrm{BEV} \mathrm{5,300} \mathrm{kg} \mathrm{CO}_{2} \mathrm{e}$ )........ 42

Figure S8. ICEV van GHG emissions sensitivity analysis for low, high and base case scenarios................................................43

Figure S9. ICEV van life cycle energy use sensitivity analysis for low, high and base case scenarios .......................................... 44

Figure S10. BEV SUV life cycle energy use sensitivity analysis for low, high and base case scenarios ........................................ 45

Table S1. Weight allocations for small $(<0.5 \mathrm{~kg})$, medium $(0.51-1.0 \mathrm{~kg})$ and large $(>1.0 \mathrm{~kg})$ electronic boards for calculating materials and manufacturing life cycle energy and GHG emissions ${ }^{1}$......

Table S2. Energy intensity and GHG emissions intensity values used to calculate life cycle energy and GHG emissions for electronic components ${ }^{1}$.....

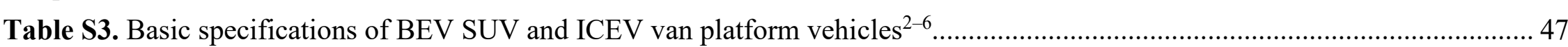

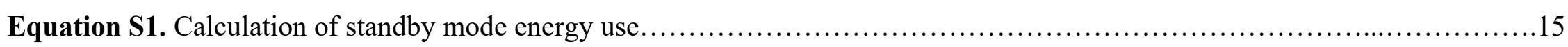




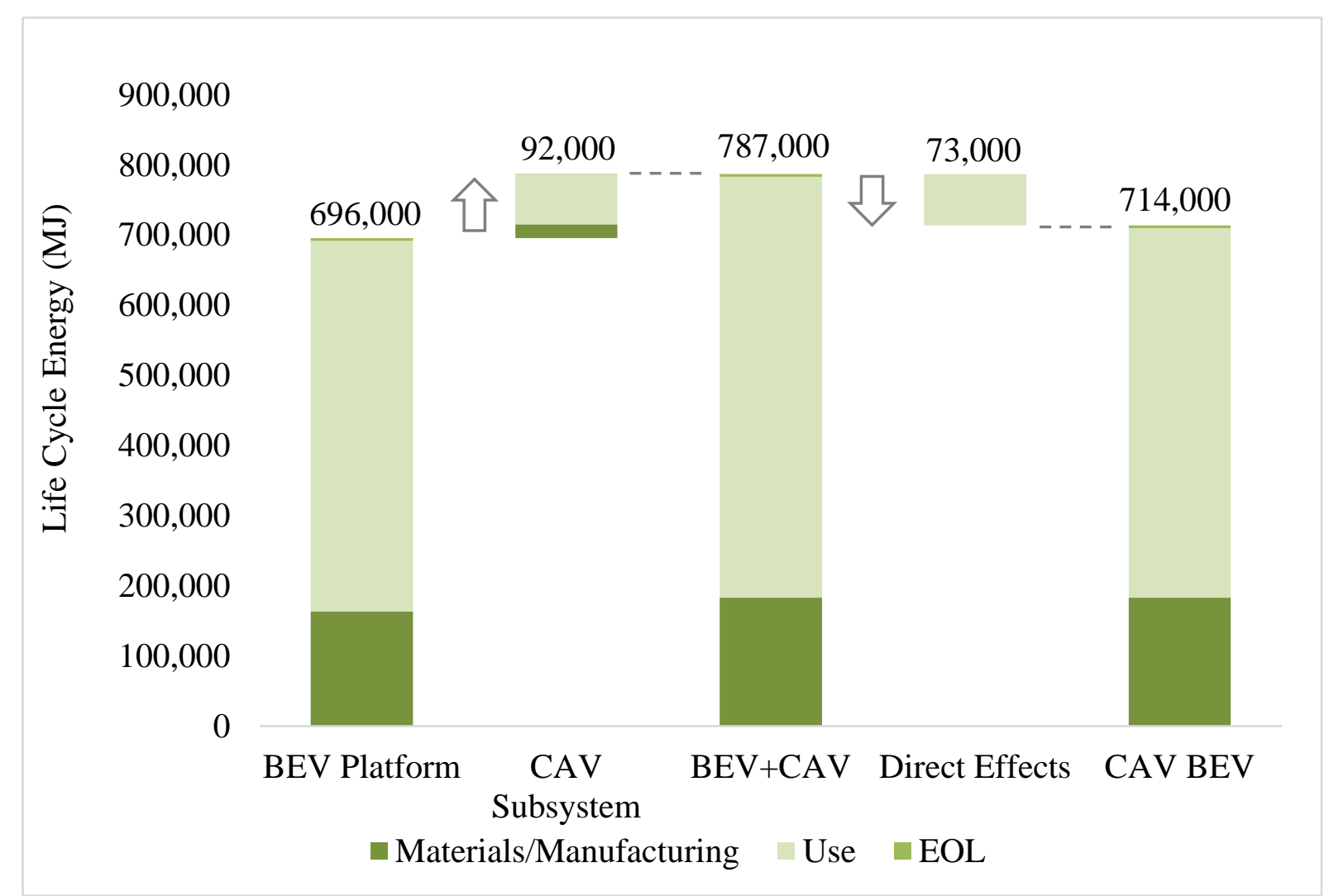

Figure S6. BEV SUV vehicle level life cycle energy burden depicting contributions from the vehicle platform, CAV subsystem and the benefits of direct effects for the BEV platform 


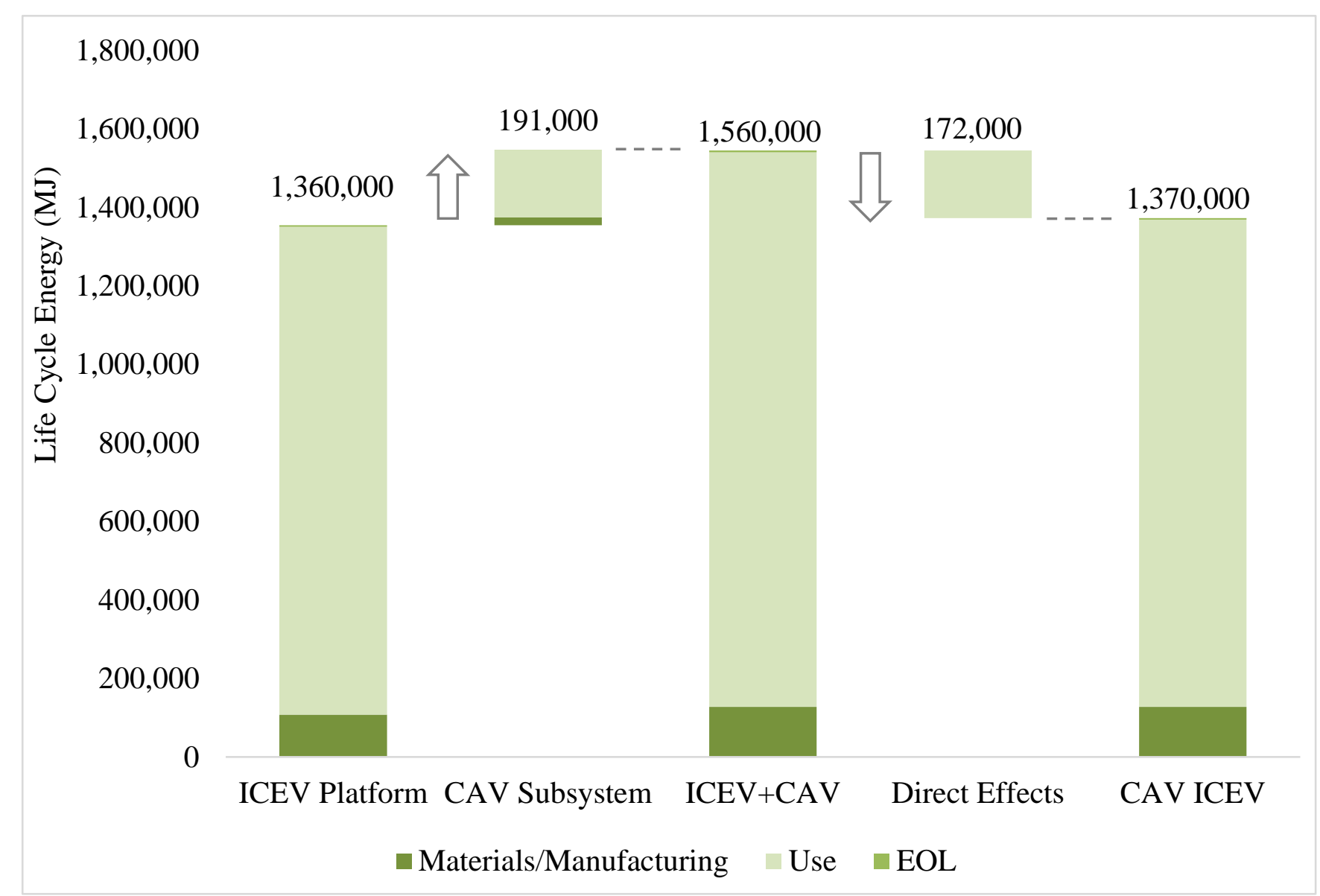

Figure S7. ICEV van vehicle level life cycle energy burden depicting contributions from the vehicle 


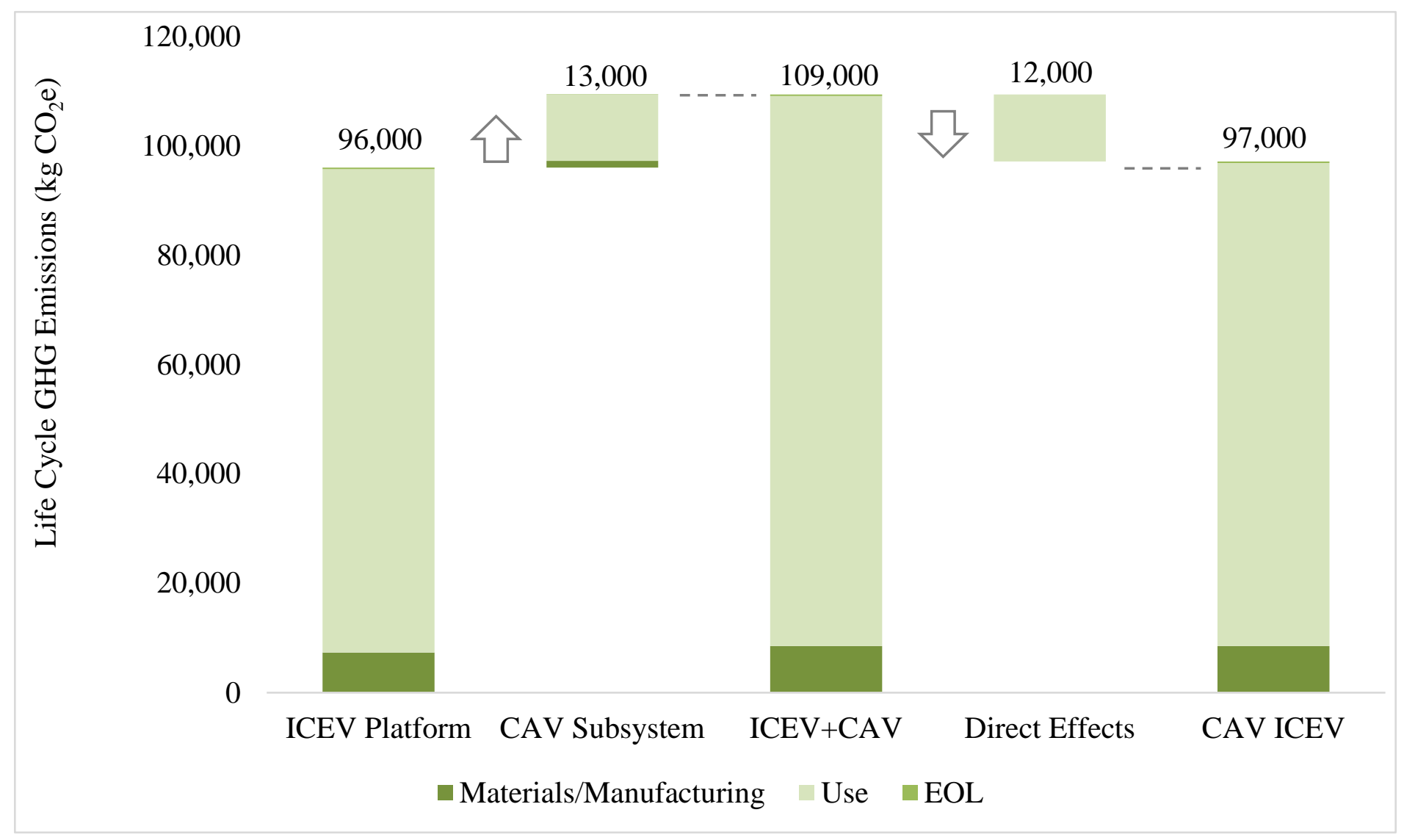

Figure S8. ICEV van vehicle level GHG emissions depicting contributions from the vehicle platform, CAV subsystem and the benefits from direct effects for the ICEV platform 

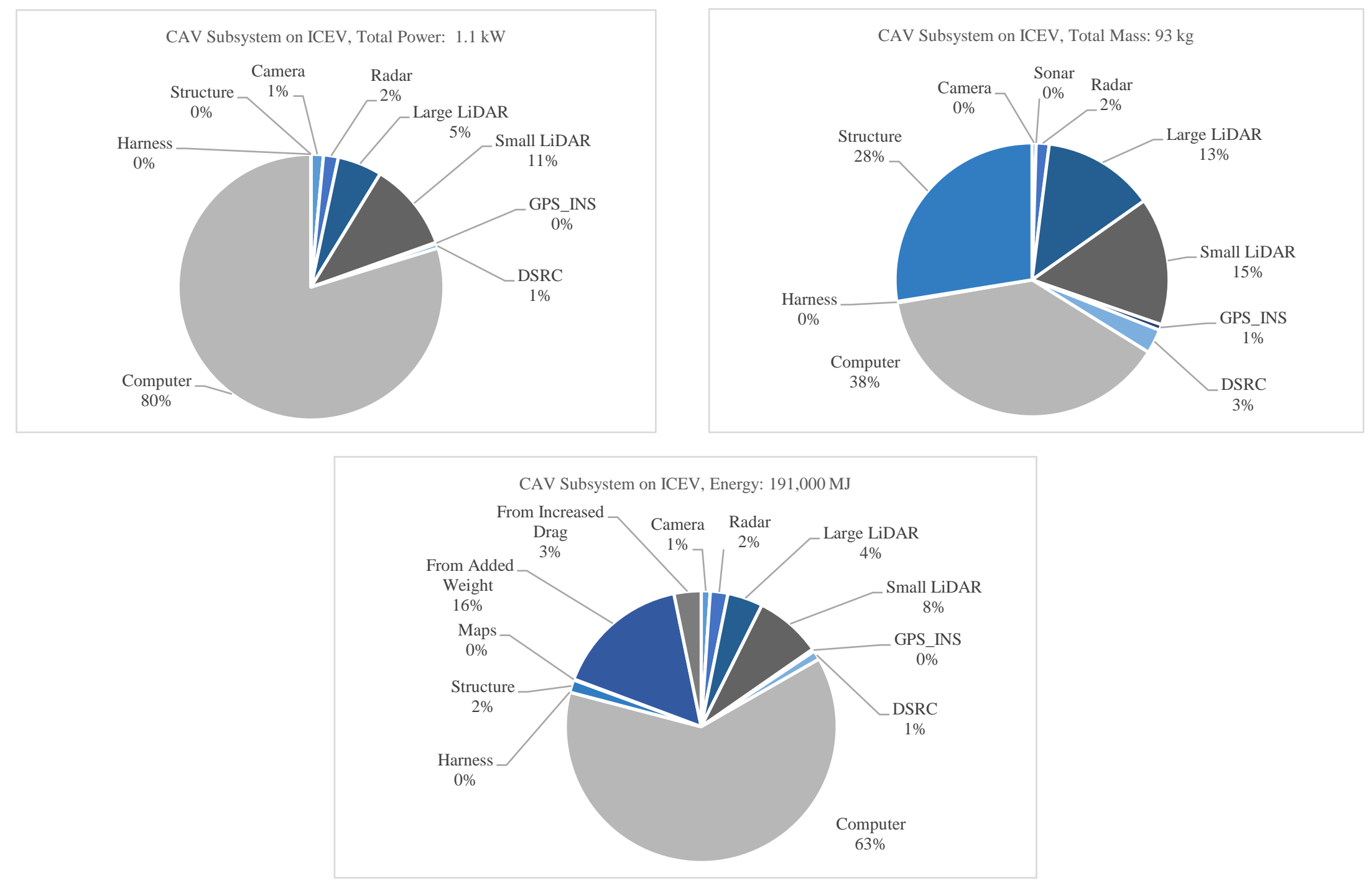

Figure S9. ICEV van subsystem contribution breakdown by percent for energy use, mass and power 

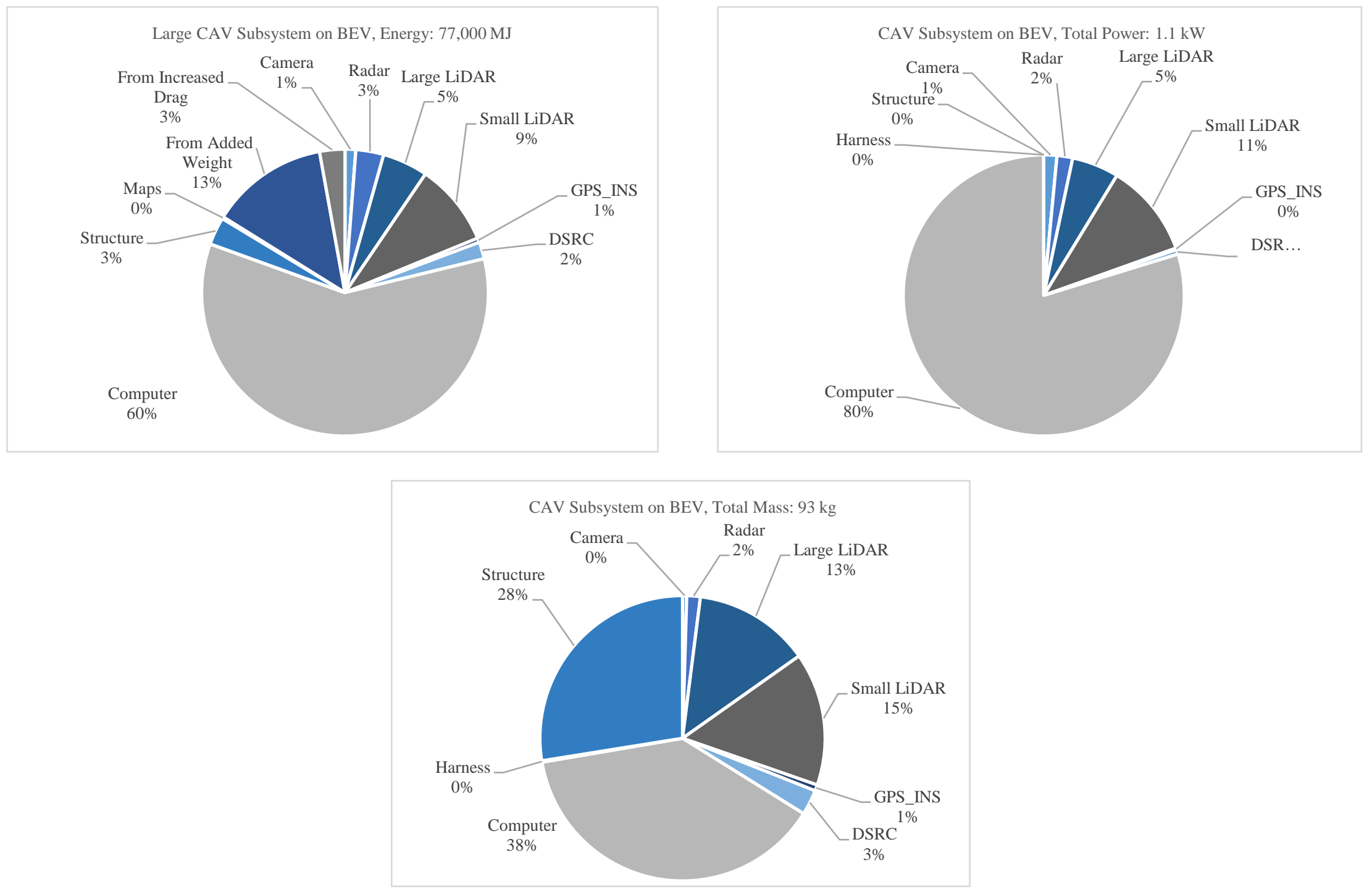

Figure S10. BEV SUV subsystem contribution breakdown by percent for energy use, mass and power 


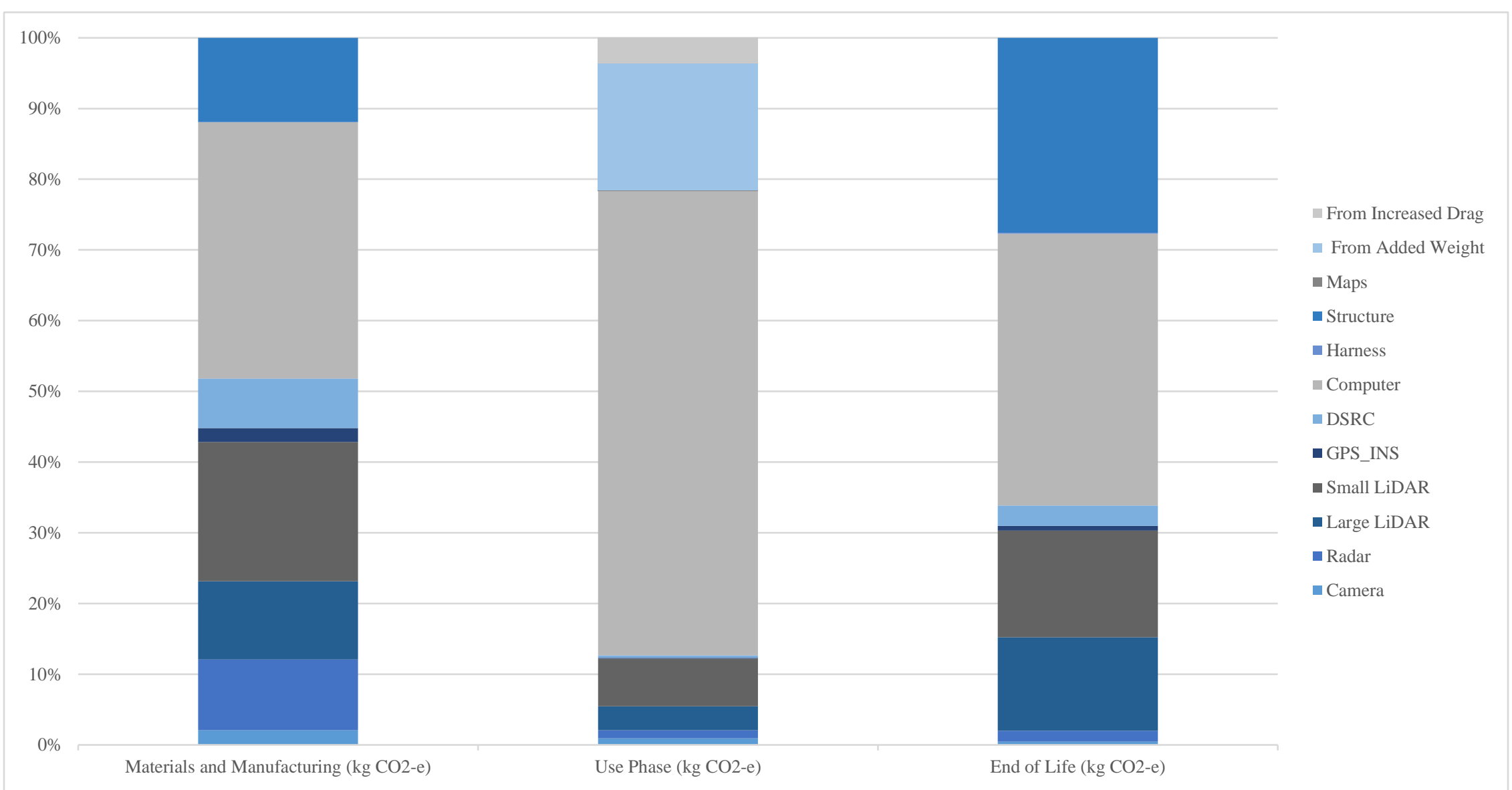

Figure S11. ICEV van platform subsystem components percent breakdown of emissions by phase $(1,200 \mathrm{~kg} \mathrm{CO} 2 \mathrm{e}, 12,000 \mathrm{~kg} \mathrm{CO} 2 \mathrm{e}$, $7 \mathrm{~kg} \mathrm{CO} 2 \mathrm{e}$ ) 


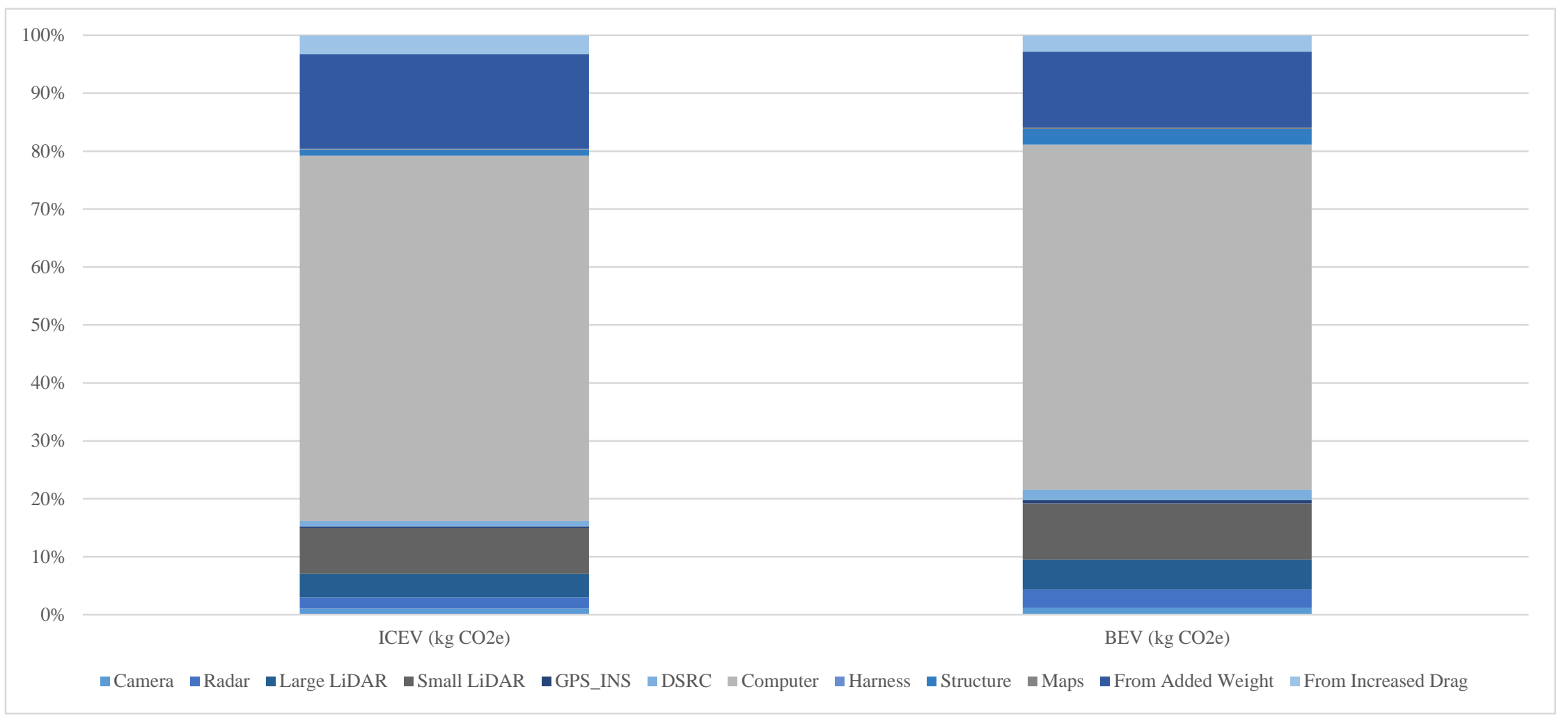

Figure S12. Comparitive subsystem component percent breakdown of emissions ( ICEV van 13,000 kg CO 2 e, BEV SUV 5,300 kg $\left.\mathrm{CO}_{2} \mathrm{e}\right)$ 


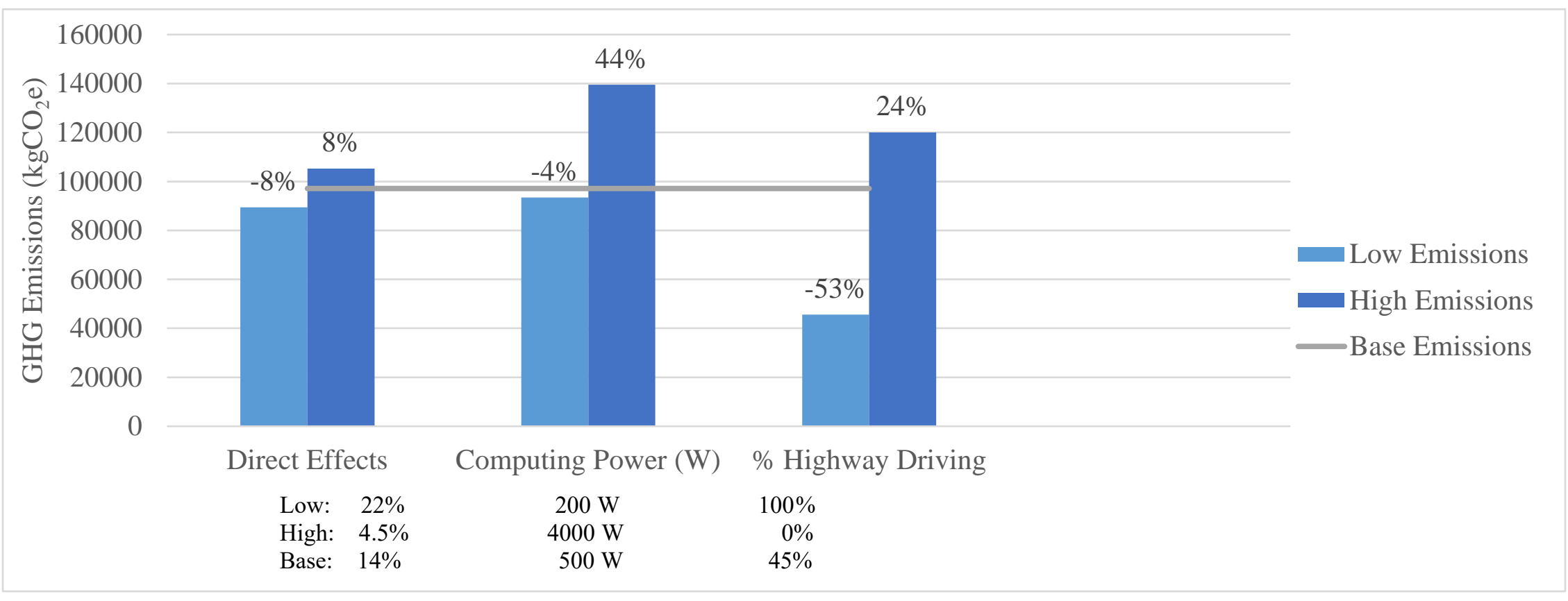

Figure S13. ICEV van GHG emissions sensitivity analysis for low, high and base case scenarios 


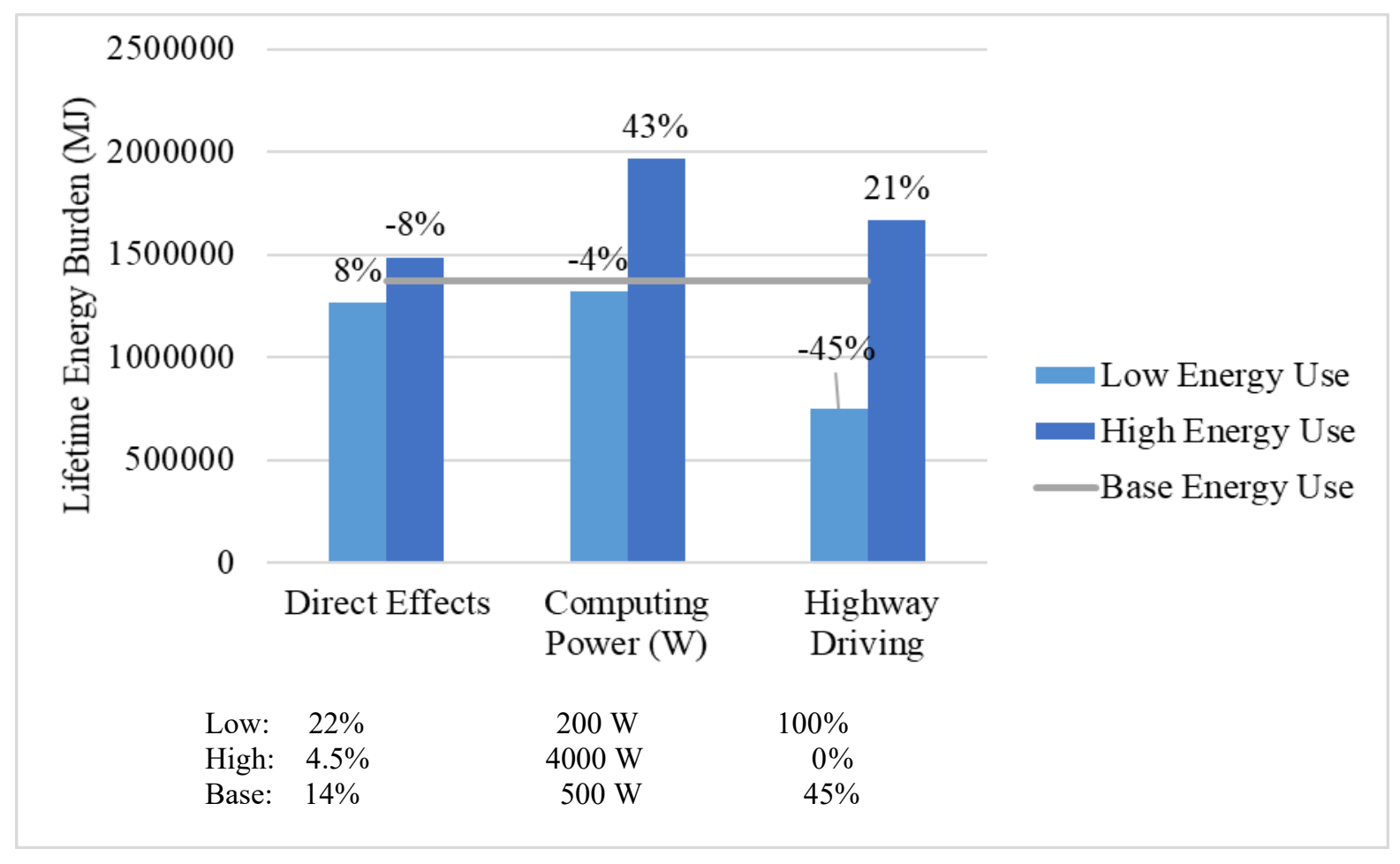

Figure 14. ICEV van life cycle energy use sensitivity analysis for low, high and base case scenarios 


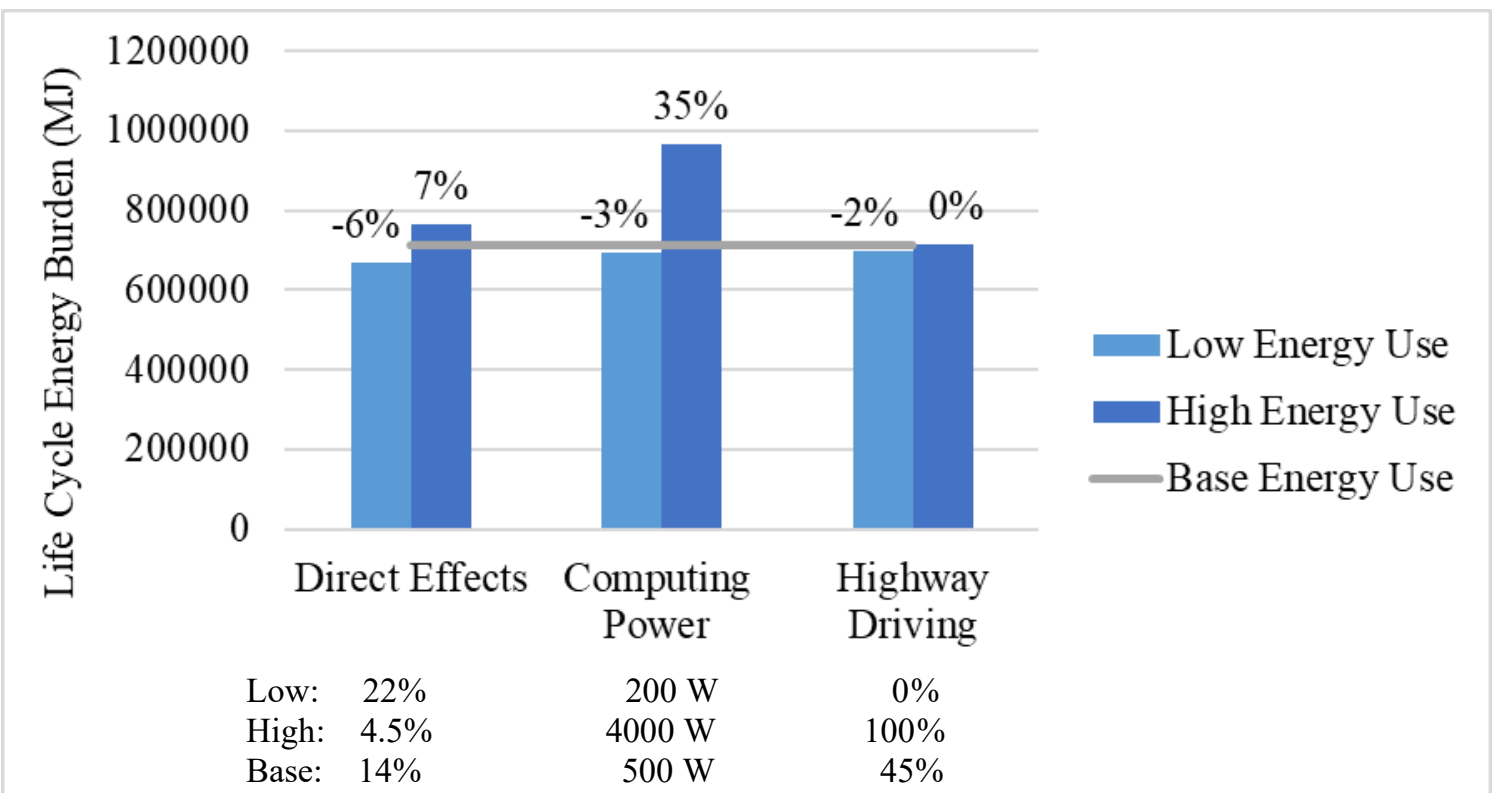

Figure S15. BEV SUV life cycle energy use sensitivity analysis for low, high and base case scenarios 
Table 4. Weight allocations for small $(<0.5 \mathrm{~kg})$, medium $(0.51-1.0 \mathrm{~kg})$ and large $(>1.0 \mathrm{~kg})$ electronic boards for calculating materials and manufacturing life cycle energy and GHG emissions ${ }^{1}$

\begin{tabular}{|l|r|r|r|}
\hline Component & Small board $(<0.5 \mathrm{~kg})$ & Medium board $(0.51-1 \mathrm{~kg})$ & Large board $(>1.0 \mathrm{~kg})$ \\
\hline PWB & $77.8 \%$ & $41.3 \%$ & $40.6 \%$ \\
\hline Power Supply & $20.0 \%$ & $55.3 \%$ & $57.7 \%$ \\
\hline IC Package & $2.0 \%$ & $3.3 \%$ & $1.6 \%$ \\
\hline IC components & $0.2 \%$ & $0.1 \%$ & $0.1 \%$ \\
\hline
\end{tabular}

Table S5. Energy intensity and GHG emissions intensity values used to calculate life cycle energy and GHG emissions for electronic components ${ }^{1}$

\begin{tabular}{|l|l|l|}
\hline \multicolumn{1}{|c|}{ Component } & \multicolumn{1}{|c|}{$\begin{array}{c}\text { Energy Intensity } \\
(\mathrm{MJ} / \mathrm{gram})\end{array}$} & \multicolumn{1}{c|}{$\begin{array}{c}\text { GHG Emissions Intensity } \\
\left(\mathrm{kg} \mathrm{CO}_{2}-\mathrm{e} / \mathrm{gram}\right)\end{array}$} \\
\hline PWB & 1.1 & 0.06 \\
\hline Power Supply & 0.51 & 0.03 \\
\hline IC Package & 11 & 0.53 \\
\hline IC components & 350 & 24 \\
\hline
\end{tabular}


Table S6. Comparison of basic specifications of BEV and ICEV platform vehicles ${ }^{2-6}$

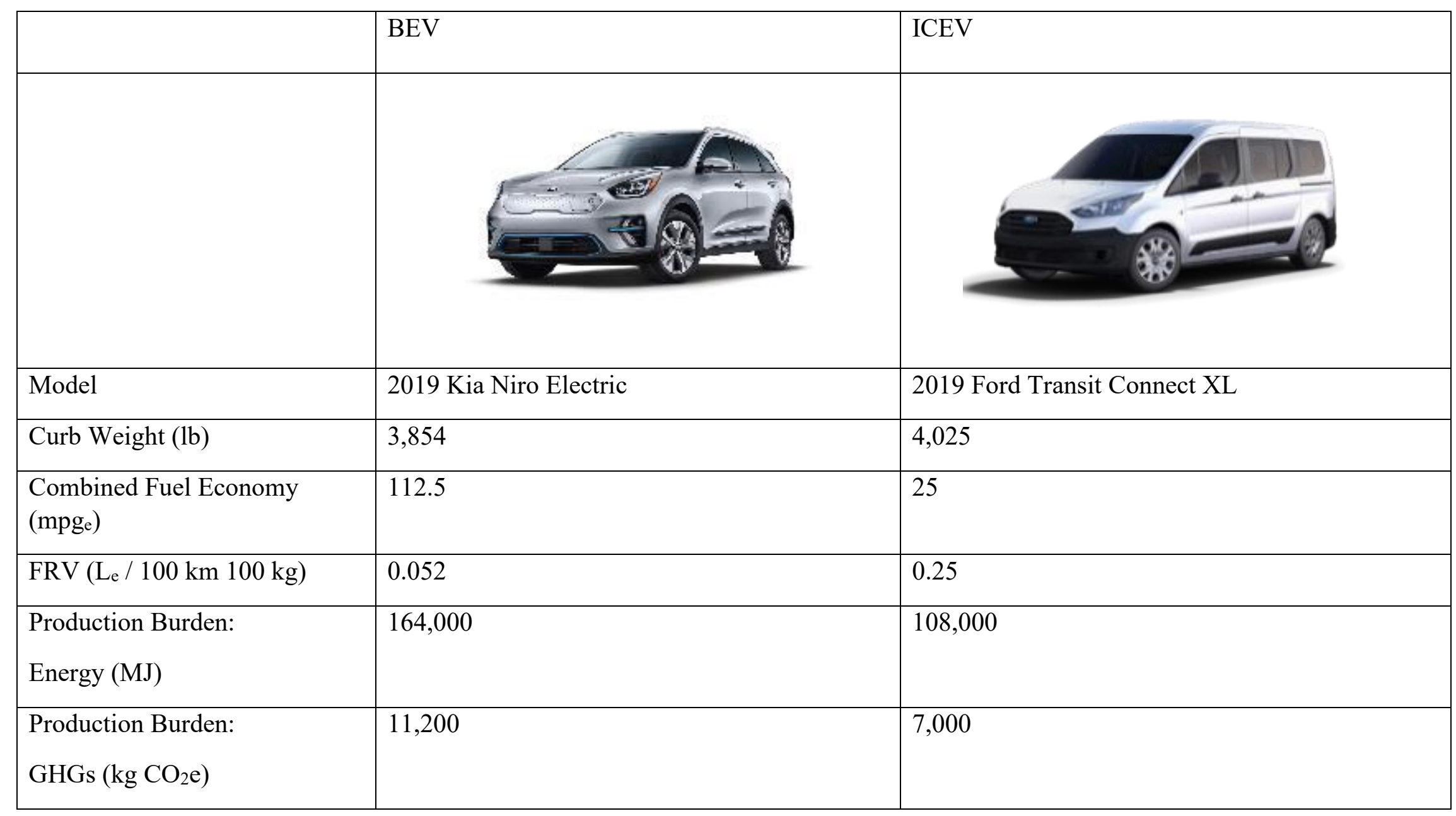


The standby power requirements were calculated based on Tesla Model 3 self reported phantom battery draining data ${ }^{7}$. The life cycle energy use for standby mode $E_{\text {standby }}$ can be represented as:

$E_{\text {standby }}=P_{\text {standby }} * t_{\text {standby }}+\left(P_{\text {standby }} * t_{\text {standby }}\right) * r_{\text {cooling }}$

Equation $S 1$

Where $P_{\text {standby }}=$ power demand for standby connectivity in kilowatts, $t_{\text {standby }}=$ time the vehicle is in standby mode in hours, and

$r_{\text {cooling }}=$ the ratio of units of cooling power to units of standby computing power. ${ }^{8}$ Note, for modeling purposes $t_{\text {standby }}$ is assumed to be all time that the vehicle is not operating; a fleet vehicle would maintain connectivity for the duration of the vehicle lifetime.

\section{References}

(1) Teehan, P.; Kandlikar, M. Comparing Embodied Greenhouse Gas Emissions of Modern Computing and Electronics Products. Environ. Sci. Technol. 2013, 47 (9), 3997-4003. https://doi.org/10.1021/es303012r.

(2) Kim, H. C.; Wallington, T. J. Life Cycle Assessment of Vehicle Lightweighting: A Physics-Based Model of Mass-Induced Fuel Consumption. Environ. Sci. Technol. 2013, 47 (24), 14358-14366. https://doi.org/10.1021/es402954w.

(3) Kim, H. C.; Wallington, T. J.; Sullivan, J. L.; Keoleian, G. A. Life Cycle Assessment of Vehicle Lightweighting: Novel 
Mathematical Methods to Estimate Use-Phase Fuel Consumption. Environ. Sci. Technol. 2015, 49 (16), $10209-10216$.

(4) Fuel Economy https://www.epa.gov/fueleconomy/text-version-gasoline-label (accessed Aug 8, 2019).

(5) Fuel Economy https://www.fueleconomy.gov/feg/PowerSearch.do?action=noform\&path=1\&year1=2019\&year2=2019\&make=Kia\&baseMod el=Niro\&srchtyp=ymm (accessed Aug 8, 2019).

(6) GREET Model; Transportation Research Center and Analysis Computing; Argonne National Laboratory: Argonne, IL, 2018.

(7) Alvarez, S. Tesla Model 3 "Phantom Drain" Compared to Model S and Model X https://www.teslarati.com/tesla-model-3phantom-drain-vampire-loss-vs-S-X/.

(8) Lin, S. C.; Zhang, Y.; Hsu, C. H.; Skach, M.; Haque, M. E.; Tang, L.; Mars, J. The Architectural Implications of Autonomous Driving: Constraints and Acceleration. ACM SIGPLAN Not. 2018, 53 (2), 751-766. https://doi.org/10.1145/3173162.3173191. 